\title{
Northern African climate at the end of the twenty-first century: an integrated application of regional and global climate models
}

\author{
Christina M. Patricola · Kerry H. Cook
}

Received: 3 December 2008/ Accepted: 25 June 2009/Published online: 15 July 2009

(c) The Author(s) 2009. This article is published with open access at Springerlink.com

\begin{abstract}
A method for simulating future climate on regional space scales is developed and applied to northern Africa. Simulation with a regional model allows for the horizontal resolution needed to resolve the region's strong meridional gradients and the optimization of parameterizations and land-surface model. The control simulation is constrained by reanalysis data, and realistically represents the present day climate. Atmosphere-ocean general circulation model (AOGCM) output provides SST and lateral boundary condition anomalies for 2081-2100 under a business-as-usual emissions scenario, and the atmospheric $\mathrm{CO}_{2}$ concentration is increased to $757 \mathrm{ppmv}$. A ninemember ensemble of future climate projections is generated by using output from nine AOGCMs. The consistency of precipitation projections for the end of the twenty-first century is much greater for the regional model ensemble than among the AOGCMs. More than $77 \%$ of ensemble members produce the same sign rainfall anomaly over much of northern Africa. For West Africa, the regional model projects wetter conditions in spring, but a midsummer drought develops during June and July, and the heat stoke risk increases across the Sahel. Wetter
\end{abstract}

This paper is a contribution to the special issue on West African Climate, consisting of papers from the African Multidisciplinary Monsoon Analysis (AMMA) and West African Monsoon Modeling and Evaluation (WAMME) projects, and coordinated by Y. Xue and P. M. Ruti.

C. M. Patricola $(\square)$

Department of Earth and Atmospheric Sciences,

Cornell University, 3152 Snee Hall, Ithaca, NY 14853, USA

e-mail: cmd58@cornell.edu

K. H. Cook

Jackson School of Geosciences, The University of Texas

at Austin, 1 University Station, C1100, Austin, TX 78712, USA conditions resume in late summer, and the likelihood of flooding increases. The regional model generally projects wetter conditions over eastern Central Africa in June and drying during August through September. Severe drought impacts parts of East Africa in late summer. Conditions become wetter in October, but the enhanced rainfall does not compensate for the summertime deficit. The risk of heat stroke increases over this region, although the threat is not projected to be as great as in the Sahel.

\section{Introduction}

As greenhouse warming continues, there is growing concern about the future climate of northern Africa. The Fourth Assessment Report of the Intergovernmental Panel on Climate Change (IPCC AR4; IPCC 2007) highlights this region as exceptionally vulnerable to climate change, especially since the population depends highly on agriculture and climate change may alter the availability of water resources.

The atmosphere-ocean general circulation model (AOGCM) simulations prepared by modeling groups around the world for the IPCC AR4 are state-of-the-art tools for studying future climate, but they do not produce projections of future climate for northern Africa with confidence. This lack of confidence derives in part from the models' difficulties in accurately capturing today's climate processes, although it has become clear that an accurate simulation of past climate variability in this region does not guarantee successful prediction (Cook and Vizy 2006a; Biasutti et al. 2008). It also arises from a concern that the AOGCMs may not simulate future global SST distributions with sufficient accuracy, since we know from studies of present day climate variability that northern Africa is 
sensitive to SST anomalies-and their gradients-in the Indian, Atlantic, and Pacific Oceans. Indeed, the AR4 AOGCM simulations do not produce a consensus about how rainfall will change due to greenhouse gas increases over northern Africa during the summer, further undermining confidence in the results.

In this paper we design and carry out simulations aimed at providing the most confident projections of future climate over northern Africa possible given our current state of understanding of the climate of this region and our ability to model that climate. The climates of West Africa and the continent-spanning Sahel are particularly complex, with pronounced thermal and moisture gradients, an intricate series of atmospheric jets, various hydrodynamic instabilities, and a demonstrated sensitivity to both global SSTAs and regional land surface processes. The region has a known propensity for abrupt climate change and decadalscale drought. The global connectivity of the region's climate combined with the influence of regional-scale structures and processes suggests an approach that combines global climate models (AOGCMs) with a regional climate model (RCM).

Here we provide a projection of climate change for the end of the twenty-first century in northern Africa that is as reliable as possible given the current state of climate system modeling (and the accuracy with which greenhouse gas emissions can be projected). We develop and apply a method for simulating future climate that addresses issues that are particular to our region of interest, but will certainly be useful applied elsewhere, using a high-resolution RCM in conjunction with output from nine AOGCMs. A detailed description of the methodology in the context of the confidence that can be placed in these model predictions is included, and the results are presented with attention to the kinds of information needed to assess impacts.

\section{Background}

The IPCC AR4 assembled and compared output from more than 20 AOGCMs run in standardized simulations of twentieth and twenty-first century climate. The precipitation projections from the AOGCMs were averaged and presented only over areas where the models satisfied a certain level of agreement. In this process, northern Africa did not emerge as a region with confident predictions of the future. For example, when forced with a modest-growth future emissions scenario, $<66 \%$ of the AR4 AOGCMs agreed whether most of northern Africa will experience wetter or drier conditions at the end of the twenty-first century. While most of these models produced modest rainfall anomalies, two were outliers that simulated extreme changes in rainfall, one wet and one dry.
In an attempt to complement the ensemble approach to building confidence in AOGCM climate prediction, Cook and Vizy (2006a) examined twentieth century integrations of the AR4 AOGCMs to select models that more accurately represent northern African rainfall and the West African monsoon system, including its interannual variability, reasoning that these models may produce more reliable projections of future climate. They chose three models that capture the region's climate relatively well, but then found that the twenty-first century rainfall projections from these three models are radically different from one another. Of the three models selected, two are the extreme outliers. This suggests that a well-validated twentieth century climate simulation, while certainly being necessary for confident prediction, may not always be sufficient.

Cook and Vizy (2006a) continued their analysis by examining the physical processes of climate change in the selected models, and found that the outlier models exhibit behaviors that are not seen in present day climate observations. While it is not impossible that one of the extreme twenty-first century scenarios will occur, it raises concern when a model diverges so far from the climate dynamics that we see operating in today's climate, especially since the climate models have been developed and tuned over decades with heavy reference to and guidance from the observed climate. With different forcing factors becoming more prominent in the future, it is not clear how strongly we can rely on analogy with the twentieth century climate to validate climate prediction.

Observational studies show that SST forcing is related to Sahel rainfall variability on interannual to decadal time scales (e.g., Lamb 1978; Folland et al. 1991), and there is evidence that climate models with prescribed SSTs are able to capture these relationships, at least in part (Vizy and Cook 2002; Giannini et al. 2003; Hoerling et al. 2006; Hagos and Cook 2008). A number of investigations have tried to understand the potential for climate change in northern Africa in terms of changes in SSTs. Cook and Vizy (2006a) examined projected warming in the Gulf of Guinea in the AR4 AOGCMs and related this warming to Sahel rainfall through a mechanism that is a prominent source of interannual variability in today's climate (e.g., Ward 1998; Vizy and Cook 2002). Biasutti et al. (2008) used 19 pre-industrial integrations of the AR4 AOGCMs to construct a bivariate linear regression model that computes Sahel rainfall as a function of Indo-Pacific SSTs and the meridional Atlantic SST gradient. Unlike, Joly et al. (2007) who find that only one of twelve of these AOGCMs captures the observed relationship between tropical Atlantic SSTs and Sahel rainfall, Biasutti et al. (2008) conclude that their statistical model has skill in simulating rainfall on all timescales in the twentieth century and for twenty-first century interannual and decadal rainfall variability over the 
Sahel. However, changes in the Indo-Pacific SSTs and the meridional Atlantic SST gradients produced by the AOGCMs fail to explain the trend in Sahelian rainfall in the twenty-first century for the majority of the AOGCMs.

In addition to an often-confusing dependence on SST forcing from three ocean basins (Atlantic, Pacific, and Indian), the climate of northern Africa is also distinguished by an especially strong coupling between the atmosphere and the land surface (e.g., Xue and Shukla 1993; Xue and Shukla 1996; Koster et al. 2004; Patricola and Cook 2007). This coupling is thought to be instrumental in determining the region's variability (e.g., Zeng et al. 1999) and its susceptibility to abrupt change (e.g., Patricola and Cook 2008). Several modeling studies suggest that positive feedbacks resulting from interactions between the landsurface and the atmosphere can amplify the climate response to forcings such as SSTs or solar variations (e.g., Doherty et al. 2000). But the transient simulations of Liu et al. (2006) suggest that strong low-frequency climate variability, rather than atmosphere/vegetation feedbacks, may be responsible for abrupt change in the region. Paeth and Thamm (2007) propose that until 2025, the impacts of land degradation and vegetation loss over tropical Africa may even be more important than global radiative heating for understanding climate change, and this is supported by Paeth et al. (2009).

These studies indicate that relying on the AR4 AOGCM projections alone may be insufficient for creating reliable predictions of the future for northern Africa. It is clear that considering climate change in terms of variability of the present day climate system is alone not enough since additional climate forcing factors are coming into play. For example, Biasutti et al. (2008) suggest that SSTs may be less influential in forcing the climate in the future and, perhaps, that greenhouse gas forcing will dominate. It is also possible that projected rainfall may depend heavily on model resolution and parameterizations, especially for land-surface/atmosphere interactions, as noted by Cook (2008) and/or the representation of convection. But, since the modeled system is highly nonlinear, attempting to take apart the role of numerous parameterizations in 21 AOGCMs would yield little insight.

The inconsistencies in northern African rainfall projections that arise from using AOGCMs alone, and the limited understanding and confidence that we have so far gained in analyzing these projections, strongly motivate the development of a different approach. This method, which uses a regional model with an optimized set of parameterizations and SST and lateral boundary anomalies from nine AOGCMs, and the confidence that can be placed in it is described in the next section. Model validation is presented in Sect. 4. In Sect. 5 we project northern African climate for the end of the twenty-first century with focus on variables most relevant for human impacts, including precipitation and heat index. Conclusions and implications are given in Sect. 6.

\section{Methodology for generating confident future climate predictions}

Decisions were made in the simulation design to enhance the reliability of the projections of future climate. There can be no guarantee that a model will produce trustworthy projections for the future, and the emissions scenarios that force the simulated climate change are uncertain, but we need to squarely address issues of uncertainty as best as we can to provide information to the impacts community that is of the highest quality possible. This section includes a detailed description of the methodology within the context of reducing uncertainty in predictions.

The regional model used for all simulations is the Weather Research and Forecasting Model (WRF; Skamarock et al. 2005) version 2.2. This model has been developed and maintained by the National Center for Atmospheric Research (NCAR). It is a non-hydrostatic model with 28 vertical levels, and the top of the atmosphere is set to $50 \mathrm{hPa}$.

The domain chosen for this study, shown in Fig. 1 with topography as resolved in the simulations, includes continental Africa and the tropical and subtropical Atlantic and Indian Oceans, extending from $53.8^{\circ} \mathrm{W}-103.8^{\circ} \mathrm{E}$ to $32.1^{\circ} \mathrm{S}-47.4^{\circ} \mathrm{N}$. The location of boundaries is carefully chosen so that large-scale circulation features over and adjacent to northern Africa fit within the domain. A large domain is chosen so that the region of interest is far from the lateral boundaries. Each simulation uses a 90-s time step and $90 \mathrm{~km}$ horizontal resolution. Previous work indicates that this resolution is sufficient for producing a

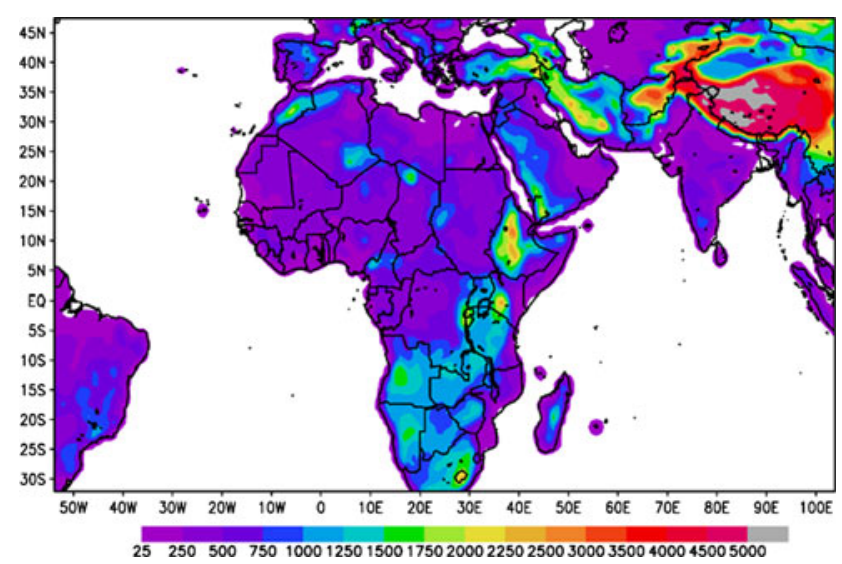

Fig. 1 Topography (m) at $90 \mathrm{~km}$ resolution on the simulation domain 
sufficiently accurate representation of the summer climate of the Sahel (e.g., Hsieh and Cook 2005, 2007, 2008; Hagos and Cook 2007) and for capturing land/atmosphere feedbacks (Patricola and Cook 2008). The horizontal resolution is finer than that of typical GCMs and provides information to aid impacts analysis on the regional scale. Integrations run for 231 days from March 15 to October 31 with the first 47 days disregarded for spin-up. Model output is saved every $3 \mathrm{~h}$.

Land surface categories are prescribed according to the 10-min resolution 24-category United States Geological Survey (USGS) data set. The WRF is modified to allow albedo to update daily, instead of the initial value remaining static. Since the resolution of the land surface characteristics is much finer than the resolution of the input surface temperature information, the small lakes covering eastern equatorial Africa are set to the closest vegetation category. This is done to prevent the prescription of unrealistic SSTs on these lakes, since information for both the twentieth and twenty-first century is not available on this space scale. Soil moisture and temperature are initialized from the European Center for Medium Range Weather Forecasting ERA-40 reanalysis (ECMWF 2002) averaged from 1981 to 2000, as previous work suggests that this produces a more accurate control simulation than when the NCEP reanalysis provides the initialization. For consistency, SSTs for the twentieth century simulation are prescribed from the monthly means of the ECMWF reanalysis averaged from 1981 to 2000 as well.

To support reliable projection of future climate, a realistic control simulation is necessary, even though recent results show that it is not sufficient for reliable prediction (Cook and Vizy 2006a; Biasutti et al. 2008). Utilizing the regional model offers the ability to optimize parameterizations and the land-surface model regionally. Several sets of parameterizations and configurations (summarized in Table 1) were tested to compliment previous modeling experience and optimize for simulation of African climate north of $10^{\circ} \mathrm{S}$. The selection of regionally appropriate parameterizations and land surface model was of critical importance in producing an accurate control simulation of the twentieth century climate. This is demonstrated by the precipitation of two tests simulations for the twentieth century. The regional model is configured exactly the same for these tests, except in test_1, the NOAH land-surface model (Chen and Dudhia 2001), Monin-Obukhov surface scheme (Monin and Obukhov 1954), and Yonsei University (YSU) planetary boundary layer scheme (Hong et al. 2006) are utilized, while in test_ 2 the RUC land-surface model (Smirnova et al. 1997; Smirnova et al. 2000), Monin-Obukhov Janjic surface scheme (Monin and Obukhov 1954; Janjic 1994, 1996, 2002), and Mellor-Yamada-Janjic planetary boundary layer (Mellor and Yamada 1982; Janjic 1990, 1996, 2002) are used. The average precipitation during May is plotted for test_1 (Fig. 2a) and test_2 (Fig. 2b), and there are clearly huge differences in the simulations depending on the choice of parameterizations. This, of course, is not to claim that one scheme is superior to another, but to illustrate that the selection of certain parameterizations has a huge impact on a simulation regionally and that the ability to configure the regional model appropriately is one great advantage over the approach of using global models alone.

While the choice of surface parameterizations and landsurface model has a strong impact on the simulation, the use of different cumulus parameterization results in relatively small differences. Two simulations were conducted using exactly the same parameterizations, except the new Kain-Fritsch cumulus scheme (Kain and Fritsch 1990, 1993) is used in one (named test_3), and in the other (named test_4) the Betts-Miller-Janjic parameterization (Betts 1986; Betts and Miller 1986; Janjic 1990, 1994, 2000 ) is used. Comparison of the May rainfall for test_3 and test_4 (Fig. 2c, d, respectively) shows that, at least for these two cumulus schemes, the choice does not have a large impact on the simulated precipitation.

Based on these tests and previous work, the physical options chosen in this study include the Mellor-YamadaJanjic planetary boundary-layer scheme (Mellor and Yamada 1982; Janjic 1990, 1996, 2002), the MoninObukhov Janjic surface-layer scheme (Monin and Obukhov 1954; Janjic 1994, 1996, 2002), the new Kain-Fritsch cumulus scheme (Kain and Fritsch 1990, 1993), and the Purdue Lin microphysics scheme (Lin et al. 1983; Rutledge

Table 1 Summary of test simulations

\begin{tabular}{lllllll}
\hline $\begin{array}{l}\text { Test } \\
\text { number }\end{array}$ & PBL scheme & Surface scheme & LSM & Convection scheme & Lateral boundaries & Domain \\
\hline 1 & YSU & Monin-Obukhov & NOAH & New KF & Climatological 1981-2000 & Excludes South Africa \\
2 & Mellor-Yamada- & Monin-Obukhov & RUC & New KF & Climatological 1981-2000 & Excludes South Africa \\
& Janjic & Janjic & & & Climatological 1981-2000 & Includes South Africa \\
3 & YSU & Monin-Obukhov & NOAH & New KF & Climatological 1981-2000 & Includes South Africa \\
4 & YSU & Monin-Obukhov & NOAH & Betts and Miller & Synoptic 1991 & Includes South Africa \\
5 & YSU & Monin-Obukhov & NOAH & New KF & & \\
\hline
\end{tabular}


(a)

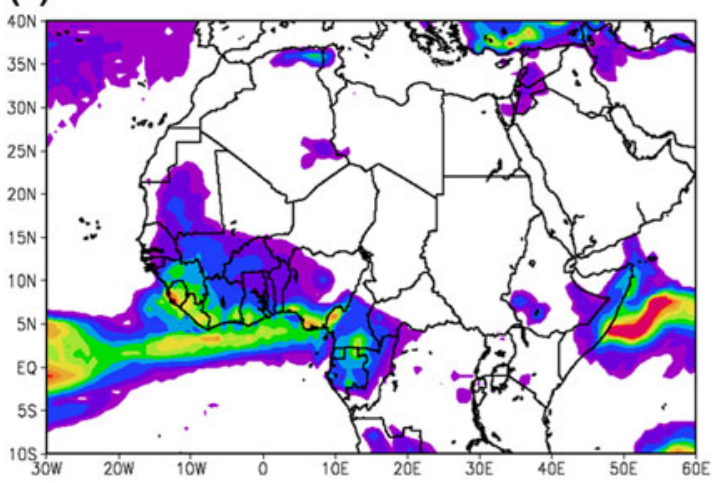

(c)

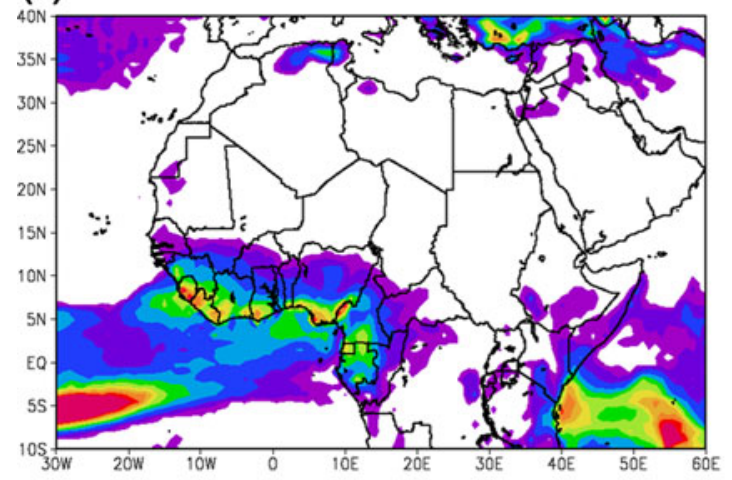

(e)

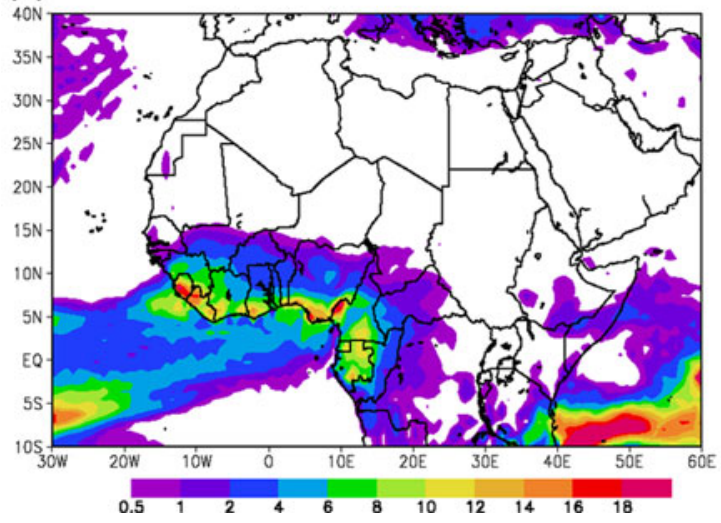

(b)

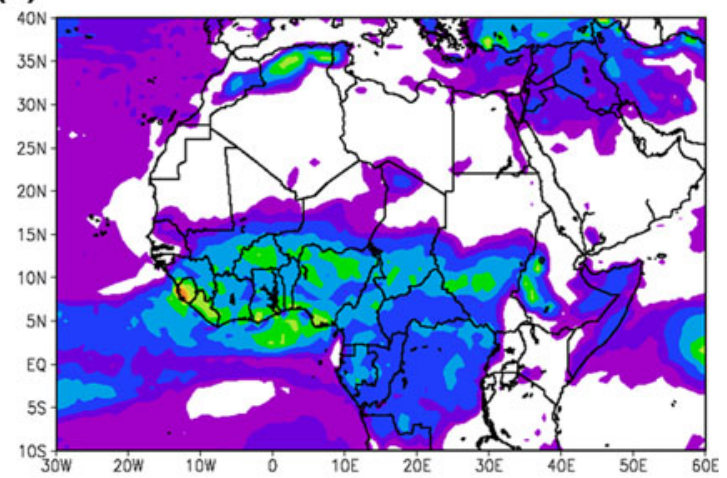

(d)

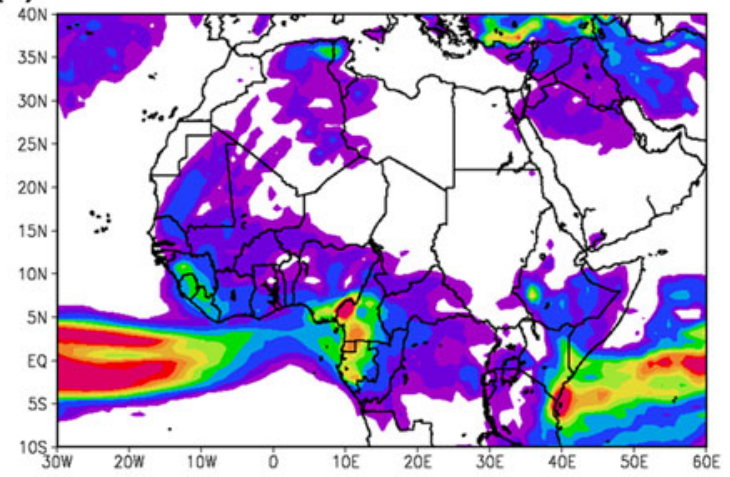

ig. 2 Precipitation rate $(\mathrm{mm} /$ day) averaged over May from a test_1, b test_2, $\mathbf{c}$ test_3, $\mathbf{d}$ test_4, and e test_5

and Hobbs 1984; Tao et al. 1989; Chen and Sun 2002). Longwave radiation is calculated by the RRTM scheme (Mlawer et al. 1997), and shortwave is represented by the Dudhia (1989) scheme. The land-surface is represented by the RUC land-surface model (Smirnova et al. 1997, 2000), which solves heat and moisture transfer equations at six levels in the soil column and energy and moisture budget equations for the ground surface.

The National Center for Environmental Prediction (NCEP)/NCAR reanalysis (Kalnay et al. 1996) is used to specify the lateral boundary conditions for the twentieth century simulation. All boundary conditions are derived from the monthly means averaged over 1981-2000 and are linearly interpolated to input to WRF at 6-hourly intervals. These "climatological" lateral boundary conditions maintain variations on the seasonal time scale, but eliminate the diurnal and synoptic effects that are represented in "synoptic" lateral boundary conditions.

Using climatological surface and lateral boundary conditions produces a simulation of the climatology by integrating for 1 year instead of several decades. This method has been used successfully in previous regional climate studies (Vizy and Cook 2002, 2003, 2005; Cook and Vizy 2006b; Patricola and Cook 2007, 2008). Vizy and Cook 
(2002) compared regional climate simulations that used present day climatological versus synoptic lateral boundary conditions over a domain similar to the one used in this study, and found that including only the seasonal scale in the lateral boundaries does not significantly impact the results within the domain. For this application, we tested the validity of this methodology by running a simulation with climatological lateral boundary conditions from 1981 to 2000 (test_3) and another with synoptic lateral boundaries from the year 1991 (test_5), with all other configurations the same. Comparison of the simulated May rainfall of test_3 (Fig. 2c) and test_5 (Fig. 2e) indicates that the use of synoptic versus climatological lateral boundary conditions results in relatively small differences in simulated rainfall, especially when compared to the influence of different surface parameterizations and land-surface models (test_1 and test_2 in Fig. 2a, b, respectively). Similar to the findings of Vizy and Cook (2002), this suggests that for this domain in the tropics, the influence of transients propagating across the lateral boundaries is relatively unimportant for the simulation of climate in the interior of the domain and justifies the use of climatological lateral boundary conditions in this study. Although transients are not included in the lateral boundary conditions, the regional model develops them (for example, African easterly waves) within the interior of the large domain. Were this method to be used for another region, it would be prudent to investigate the use of climatological versus synoptic lateral boundary conditions for that domain.

The method developed in this study to produce future climate projections with improved confidence combines the strengths of regional and global climate modeling. For simulating the future, integrations are performed by the regional model with SSTs and global connectivity supplied by the state-of-the-art AOGCMs through anomalies in surface and lateral boundary conditions.

Another feature of the simulation design that is aimed at improving the reliability of the projections is the ensemble approach. Typically when working with GCMs, ensembles are used to give a measure of robustness or a range for projections. GCM ensembles are generated by integrating multiple simulations with the same physical parameterizations and forcings, but slightly different initial conditions. The spread of the ensemble members is interpreted as a measure of uncertainty. We draw on that approach to develop an ensemble simulation design for regional climate modeling. Here, nine RCM ensemble members are created by using anomalies in surface and lateral boundary conditions from nine AOGCM simulations. In this way, uncertainties associated with the details of the AOGCMs' projections of SSTs and lateral boundary conditions are taken into account to provide a range of behavior in the RCM. When the ensemble members agree, one builds confidence that the results are not depending on the unknowns, in our case, on the different lateral and surface boundary conditions. Boundary conditions are derived from the following AOGCMs which are included in the World Climate Research Programme's (WCRP's) Coupled Model Intercomparison Project phase 3 (CMIP3) multimodel dataset (Meehl et al. 2007) and are archived by the Program for Climate Model Diagnosis and Intercomparison: CCCMA_CGCM3.1, CNRM-CM3, ECHAM/ MPI-OM, GFDL-CM2.0, MIROC3.2(medres), MRICGCM2.3.2, NCAR_CCSM, NCAR_PCM, and UKMOHadCM3.

For the future climate simulations, which represent the end of this century, the 2081-2100 average $\mathrm{CO}_{2}$ concentration based on the SRESA2 emissions scenario is prescribed. This scenario estimates a relatively high emission rate of $\mathrm{CO}_{2}$ and high population growth. We choose this emissions scenario so that projections essentially represent inaction on the part of the world community and provide useful information for impacts planning. Another advantage to choosing a high emissions scenario is that the future signal is likely to be clearer than if a low emissions scenario were chosen. In the A2 scenario, the atmospheric $\mathrm{CO}_{2}$ concentration increases from $330 \mathrm{ppm}$ in the twentieth century integration to 757 ppm for the 2081-2100 mean. Effects of other greenhouse gasses and aerosols are not included. Justification for the selection of one emissions scenario is provided by GCM simulations that suggest that over West Africa uncertainties in the prescription of SSTs dominate the uncertainty of emissions scenario chosen (Caminade et al. 2006).

SST and lateral boundary conditions taken from the AOGCM simulations are applied as anomalies to the ECMWF and NCEP/NCAR reanalysis present day climatologies, respectively, and are used to produce the future (end of the twenty-first century) climate. Our approach is different from the traditional dynamical downscaling method, which would produce nine control simulations using SST and lateral boundary conditions directly from the twentieth century simulations of the AOGCMs, and then nine twenty-first century simulations. We did not adopt that strategy because confidence in the simulations is promoted by having an accurate simulation of region's climate processes in the control ("present day") simulation, and using lateral boundary conditions directly from AOGCMs seriously degrades the control simulation in other regional models including the Regional Climate Model (RegCM; Seth and Rojas 2003; Rojas and Seth 2003) as well as the Mesoscale Model 5 (MM5; Cook and Vizy 2008).

For each twenty-first century ensemble member, monthly SST distributions are calculated by adding the monthly SSTAs derived from the AOGCM to the observed monthly climatology as represented in the ECMWF 
reanalysis. The SSTAs from the AOGCMs are the 20812100 average forced by the SRESA2 emissions scenario minus the 1981-2000 average from the twentieth century (called the 20C3 M) simulations. Figure 3 shows the JuneAugust averaged SSTAs from the selected nine AOGCMs. The SSTAs exhibit substantial variability in space, although generally the tropical Indian Ocean warms more than the tropical Atlantic Ocean, except in the CNRMCM3 model (Fig. 3c). There is a considerable range of SSTAs, from about 1 to $4 \mathrm{~K}$. While there are differences in the spatial distribution and magnitude of the SSTAs among the AOGCMs, the models are consistent in that they all project warmer SSTs at the end of the twenty-first century.

Lateral boundary constraints for the twenty-first century simulations are derived similarly to the SST distributions, as monthly anomalies. Values for temperature, zonal and meridional wind, geopotential height, and relative humidity are taken from the AOGCM simulations for 1981-2000 and 2081-2100, differenced, interpolated to the reanalysis grid, and then applied as anomalies to the NCEP/NCAR reanalysis values along the lateral boundaries of the RCM. For the AOGCMs that include quantities interpolated below the local ground surface, the application of anomalies to the reanalysis is straightforward. For the AOGCMs that have missing information below the local ground surface, the anomaly from the lowest level provided by the AOGCM is applied to the reanalysis value.

One concern with this method of creating lateral boundary conditions is that information is taken from only one point in the AOGCM, making it possible to introduce small-scale circulation anomalies generated by the AOGCM. To insure against this possibility, regions located along the boundaries of the RCM domain (Fig. 1) were visually inspected in each AOGCM simulation for the twentieth and twenty-first century to be sure there are no local circulation features present.

\section{Model validation}

The ability of the regional model to represent the observed northern African climate is assessed to support confidence in the results. Particular attention is devoted to the validation of precipitation, since this is such an important variable for human impacts and is also one of the more difficult variables to simulate. Monthly average rainfall of (a)

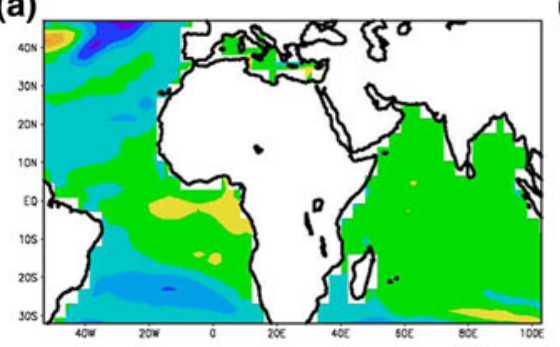

(d)

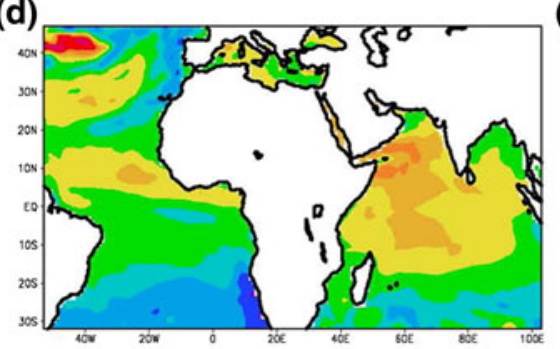

(g)

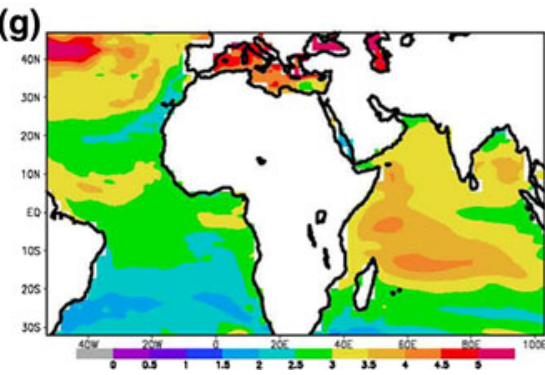

(b)

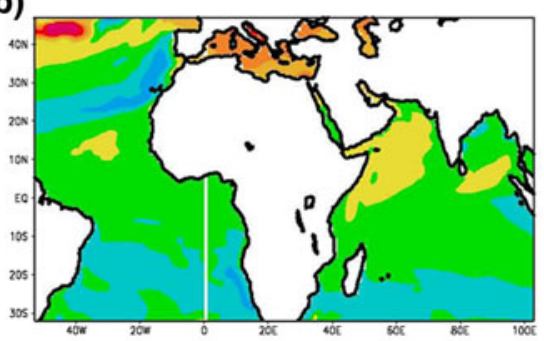

(e)

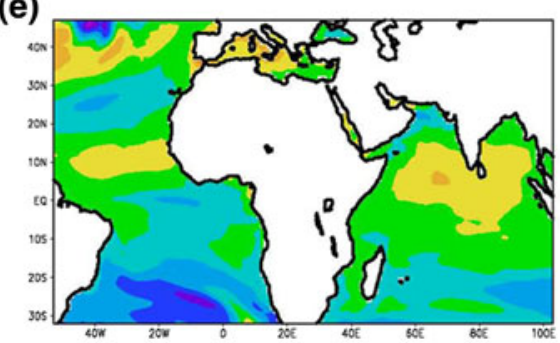

(h)

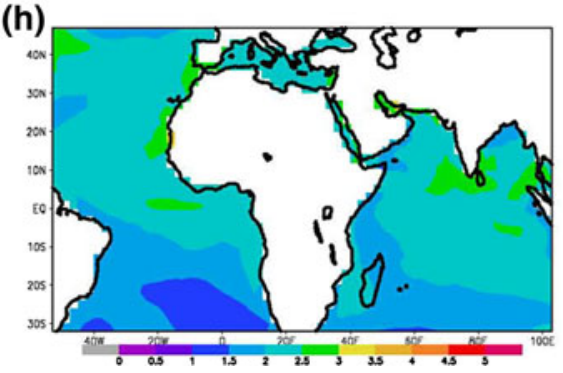

(c)

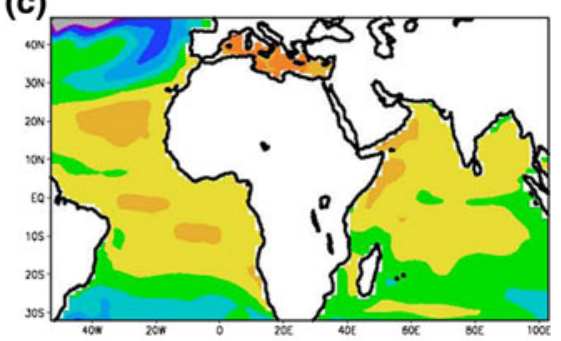

(f)

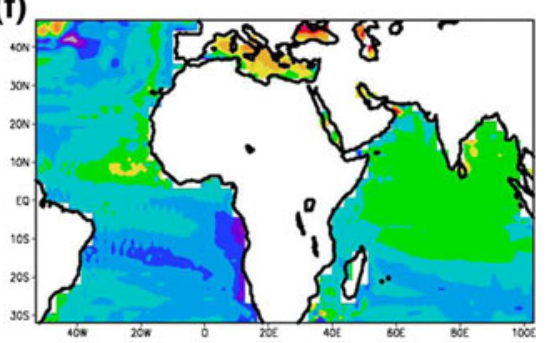

(i)

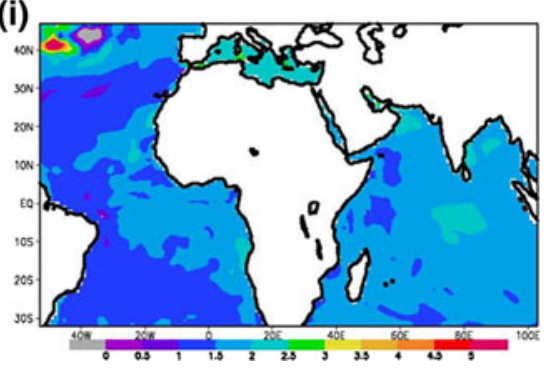

Fig. 3 SST anomalies averaged June through August calculated as the difference between the 2081-2100 averaged SST forced by the SRES A2 scenario minus the 1981-2000 averaged SST derived from a CCCMA_CGCM3.1, b NCAR_CCSM, c CNRM-CM3, d ECHAM/ MPI-OM, e GFDL-CM2.0, f UKMO-HadCM3, g MIROC3.2 (medres), h MRI-CGCM2.3.2, i NCAR_PCM 
the twentieth century regional model simulation is compared to observations, as well as to twentieth century AOGCM simulations. The ability of the regional model to simulate near-surface air temperature and circulation over northern Africa is also assessed.

Two rainfall data sets are used to include coverage over the ocean and high-resolution information over land (Fig. 4a-c). Precipitation from the monthly rain gaugederived Climate Research Unit data set (CRU; New et al. 1999), averaged over the years 1971-1990, is available over land only on a grid of $0.5^{\circ} \times 0.5^{\circ}$. Rainfall rates over the ocean are given by the monthly Global Precipitation Climatology Project (GPCP; Adler et al. 2003) Version 2 Combined Precipitation data set, averaged from 1981 to 2000. The GPCP data set covers a grid of $2.5^{\circ} \times 2.5^{\circ}$ and combines rainfall estimates from satellites and rain gauges. To maintain the resolution of the RCM rainfall, the precipitation from the RCM is presented on its $90 \mathrm{~km}$ grid.

Observed rainfall maxima along the Guinean Coast $\left(10^{\circ} \mathrm{W}, 10^{\circ} \mathrm{E}\right)$ with additional maxima over Ethiopia and the Central African Republic during May and June (Fig. 4a), are represented well in the RCM (Fig. 4d). The strong meridional precipitation gradient observed over the African continent between $10^{\circ} \mathrm{N}$ and $15^{\circ} \mathrm{N}$ (Fig. 4a) is also captured (Fig. 4d). In July and August, the observed precipitation maxima (Fig. 4b) are more intense than in May and June, and the $0.5 \mathrm{~mm} /$ day isohyet is located near $18^{\circ} \mathrm{N}-20^{\circ} \mathrm{N}$. The African rainfall maxima are also stronger in the regional model, but the position of the $0.5 \mathrm{~mm} /$ day isohyet is farther south than in the observations (Fig. 4e). The rainfall maximum remains over the Guinean Coast region and Sahelian precipitation is underestimated, with the implication that potential future drying over the Sahel during mid-summer may be underestimated. In September and October rainfall rates decrease and the $0.5 \mathrm{~mm} /$ day isohyet recedes southward in both the observations and model (Fig. 4c, f, respectively).

We also compare the RCM rainfall with a subset of the AOGCM simulations (Fig. 5). Based on the analysis of (Cook and Vizy 2006a), examples are shown from two models that do not validate well over northern Africa, the UKMO-HadCM3 and GISS_AOM in Fig. 5a, b, respectively, and two models that do validate well, the fluxadjusted MRI-CGCM2.3.2 and MIROC3.2(medres) in Fig. 5c, d, respectively. The RCM clearly produces a more realistic representation of rainfall in July and August compared with some AOGCMs, which erroneously simulate rainfall maxima over the Gulf of Guinea instead of over land (Fig. 5a) or do not simulate a West African rainfall maximum at all (Fig. 5b). The quality of the simulated rainfall is comparable among the RCM, MRICGCM2.3.2, and MIROC3.2(medres). While the landbased rainfall maxima of MRI-CGCM2.3.2, the regional model, and MIROC3.2(medres) are weaker, slightly stronger, and much stronger than observed, respectively, these differences may be within the error of the (a)

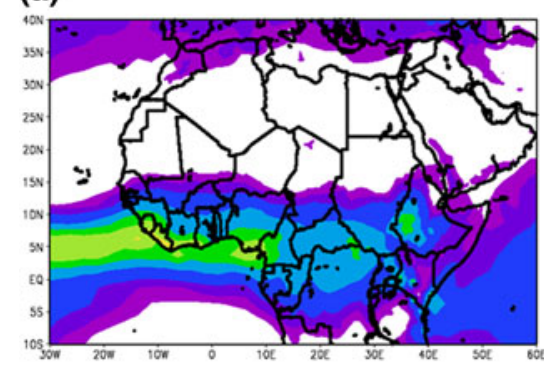

(d)

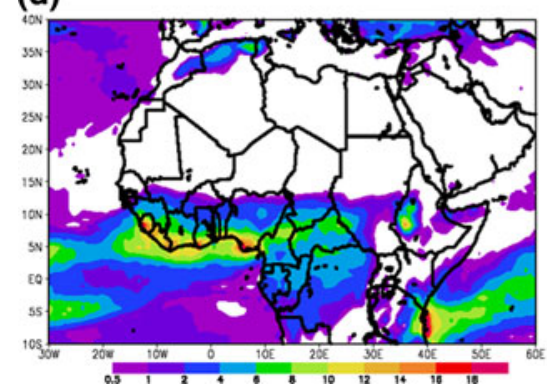

(b)

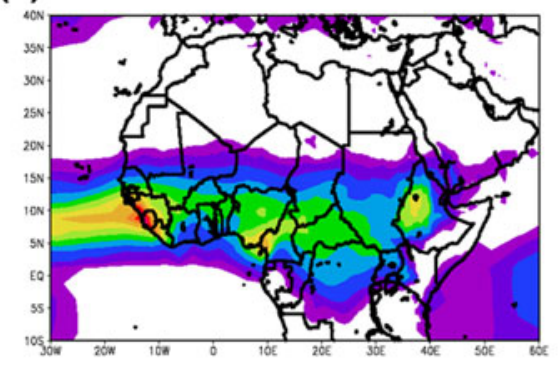

(e)

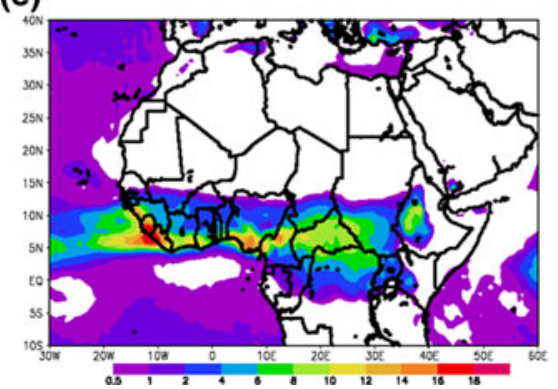

(c)

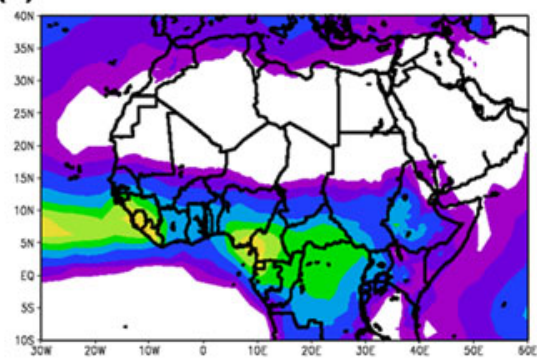

(f)

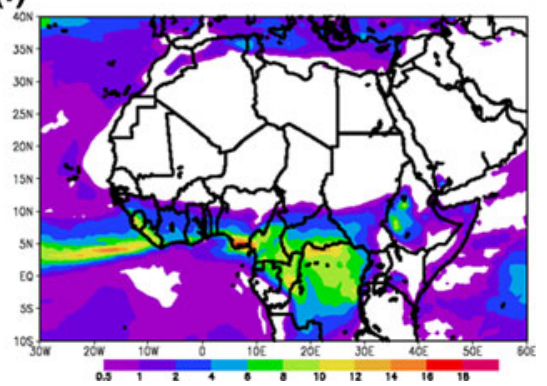

Fig. 4 Precipitation rate ( $\mathrm{mm} /$ day) from the CRU data set over land, averaged over $1971-1990$ on a $0.5^{\circ} \times 0.5^{\circ}$ grid and from the GPCP Version 2 data set over ocean, averaged over 1981-2000 on a $2.5^{\circ} \times 2.5^{\circ}$ grid during a May and June, $\mathbf{b}$ July and August, and $\mathbf{c}$
September and October. Precipitation rate ( $\mathrm{mm} /$ day) from the twentieth century RCM simulation on a $90 \mathrm{~km}$ grid during d May and June, e July and August, and f September and October 
(a)

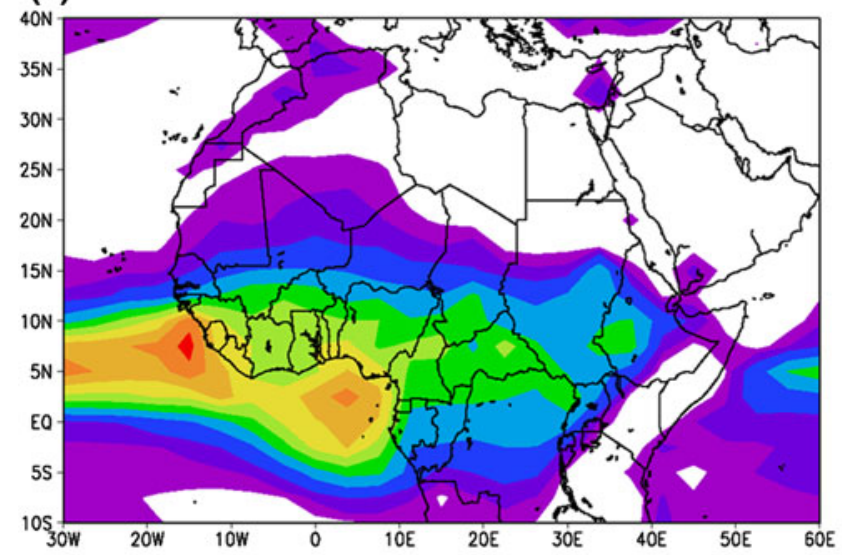

(c)

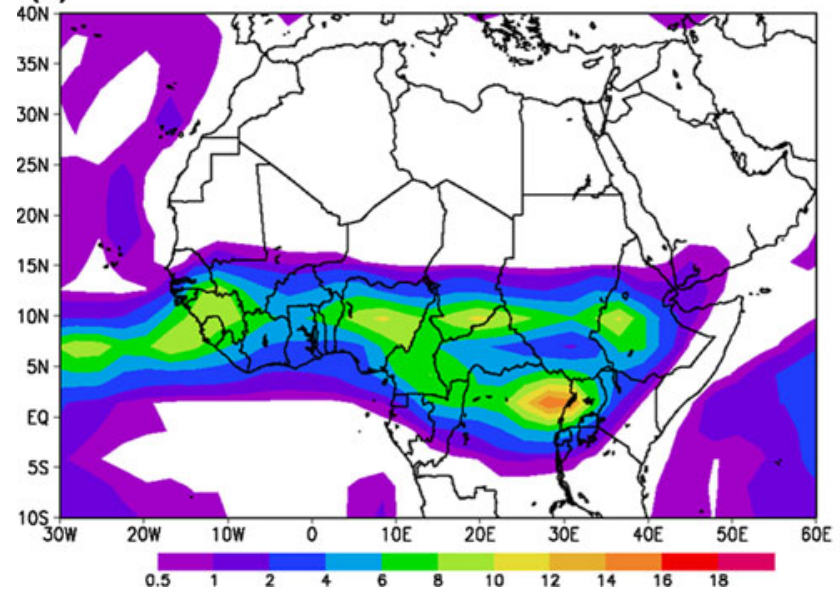

(b)

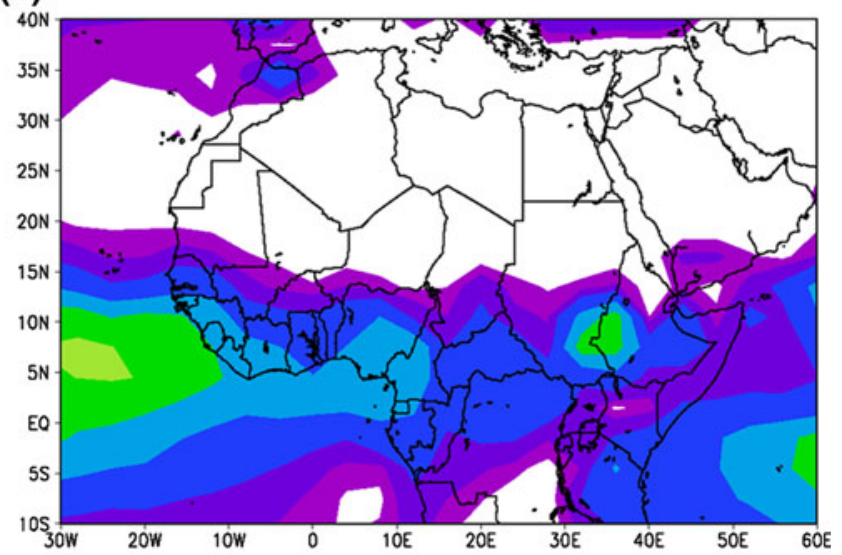

(d)

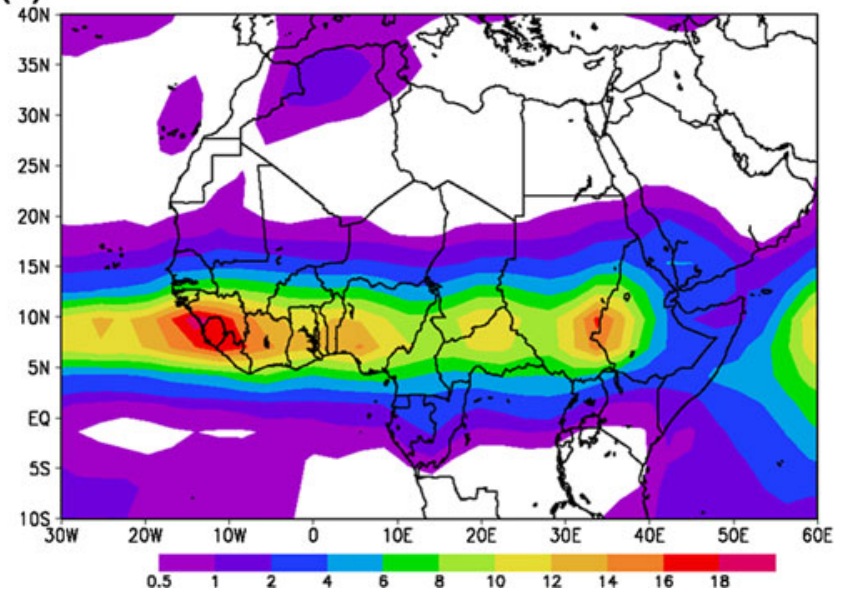

Fig. 5 Simulated precipitation rate (mm/day) from a UKMO-HadCM3, b GISS_AOM, c MRI-CGCM2.3.2, and d MIROC3.2(medres) models averaged over July and August of 1981-2000

observations, which are based on a relatively sparse network of rain gauges.

Validation of near-surface air temperature is presented since it is a critical variable for evaluating future impacts. The twentieth century RCM simulation is compared to the ECMWF ERA-40 reanalysis (ECMWF 2002), since that reanalysis provided the SSTs for the twentieth century simulation. Figure 6a and d show near-surface air temperature averaged over May and June from the reanalysis and the twentieth century RCM simulation, respectively. The reanalysis places the warmest regions over Mauritania and Mali in West Africa, Sudan and Egypt in North Africa, and the Arabian Peninsula, and the RCM simulates the location and magnitude of these maxima well. The regional model also accurately places the coolest temperatures over the east African highlands, but produces warmer temperatures than in the reanalysis over equatorial Africa. Modeled temperatures are warmer than the reanalysis over the Sahel in July and August when simulated rainfall is weaker than observed. The seasonality in near-surface air temperature is fairly well represented in the RCM, although in northwestern Africa the reanalyzed temperature is warmer in July-August (Fig. 6b) than during May-June (Fig. 6a), while this is reversed in the regional model (Fig. 6d, e). Despite these discrepancies, the RCM performs reasonably well.

The NCEP/NCAR reanalysis is used to validate circulation and geopotential height fields in the RCM since lateral boundary conditions were derived from that reanalysis. Since observations are relatively sparse over northern Africa we expect that the magnitudes of wind and geopotential height maxima and minima may be slightly different between the RCM simulation and the reanalysis. Differences may also be related to the finer resolution of the $\mathrm{RCM}(90 \mathrm{~km})$ compared to the reanalysis $\left(2.5^{\circ} \times 2.5^{\circ}\right)$.

The regional model reproduces the features of the West African summer monsoon and northern African circulation realistically. Figure 7a and d show the reanalyzed and simulated geopotential height and wind field at $925 \mathrm{hPa}$ 
(a)

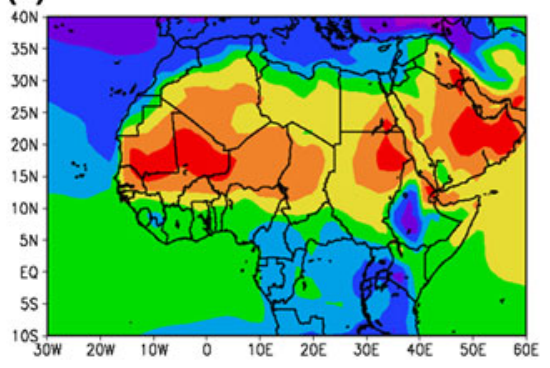

(d)

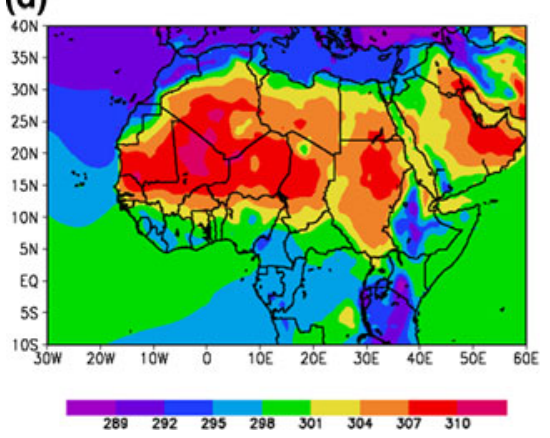

(b)

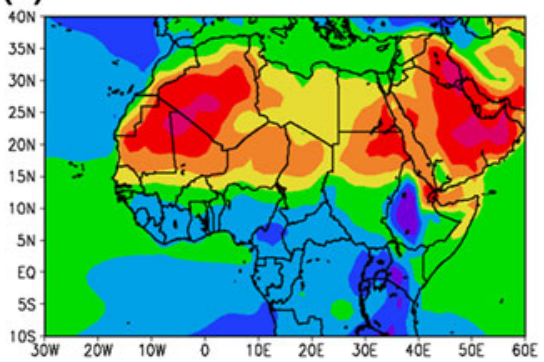

(e)

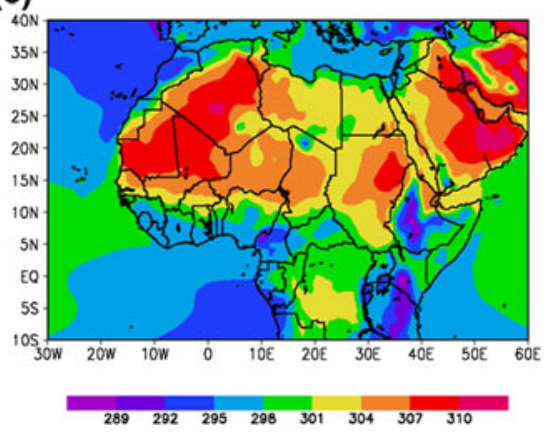

(c)

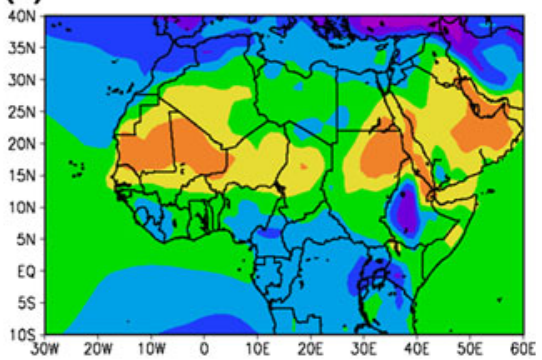

(f)

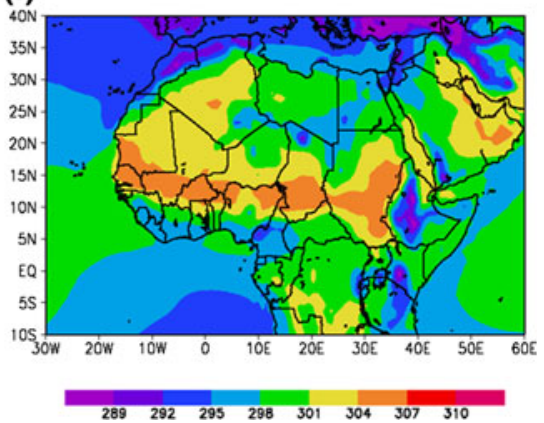

Fig. 6 Near-surface air temperature $(\mathrm{K})$ averaged over a May-June, b July-August, and c September-October of 1981-2000 from the ECMWF reanalysis and over c May-June, d July-August, and e September-October from the twentieth century RCM simulation

averaged from June through September, respectively. The shallow thermal low at about $15^{\circ} \mathrm{N}$ is slightly weaker in the RCM, and the subtropical high (near $35^{\circ} \mathrm{N}$ and $30^{\circ} \mathrm{W}$ ) is somewhat stronger than in the reanalysis. Over West Africa, the reanalyzed southerly monsoon winds from the Gulf of Guinea converge with the northerly winds from the Mediterranean region near $15^{\circ} \mathrm{N}$, and this is captured in the twentieth century simulation, but with stronger northerlies and a convergence zone located about two degrees farther south which is consistent with the precipitation issues previously discussed. Another important feature of the low-level flow which provides an important moisture source for the Sahel (Patricola and Cook 2007) is the lowlevel westerly jet off the west coast of Africa near $12.5^{\circ} \mathrm{N}$ (Grodsky et al. 2003). It is barely discernable in the reanalysis, perhaps because of the coarser resolution, and more apparent in the RCM simulation. The subtle westerly flow over Central Africa is similar between the reanalysis and the RCM. Over East Africa, the Somali jet is also well represented in the twentieth century simulation.

The divergent Saharan high overlays the low-level thermal low near $600 \mathrm{hPa}$, as seen in Fig. 7b. The African easterly jet, which forms over the strongest surface temperature gradients when Coriolis accelerations act on the northerly outflow from the Saharan High (Cook 1999), is located at about $15^{\circ} \mathrm{N}$. Both the Saharan high and the African easterly jet are represented more strongly, but reasonably, in the RCM (Fig. 7e). At $200 \mathrm{hPa}$, both the reanalysis and the model (Fig. 7c, f, respectively) produce high pressure over the Arabian Peninsula extending over northern Africa, and the associated tropical easterly jet located near $15^{\circ} \mathrm{N}$.

In summary, the RCM produces a satisfactory simulation of the twentieth century summer climate of northern Africa, comparable to or better than that of the current generation of AOGCMs and suitable for applications to study the future climate of northern Africa on regional space scales.

\section{Results}

Results from the regional model twentieth century and twenty-first century climate simulations described in Sect. 3 are presented, including comparisons with some results from the IPCC AR4 reports. Focus is on quantities that have the most impact on humans and agriculture, including monthly rainfall, extreme rainfall events, nearsurface air temperature, and heat index.

\subsection{Precipitation}

Monthly ensemble mean twenty-first century minus twentieth century precipitation anomalies derived from the regional model are plotted in Fig. 8. Only precipitation anomalies for which seven or more (77\% or greater) of the nine ensemble members produce the same sign are shown. Areas where $<77 \%$ of the ensemble members agree on the 
(a)

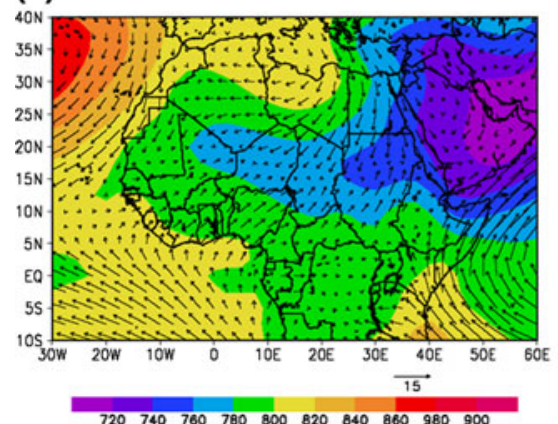

(d)

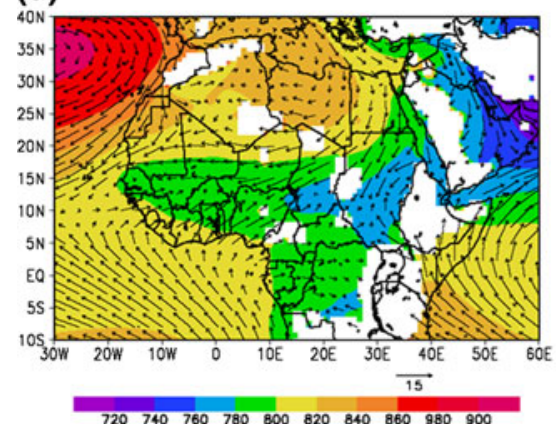

(b)

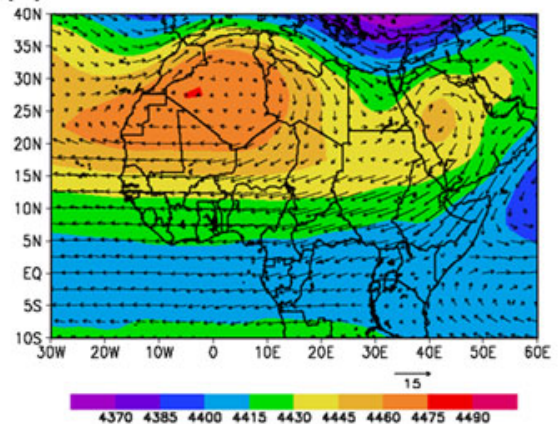

(e)

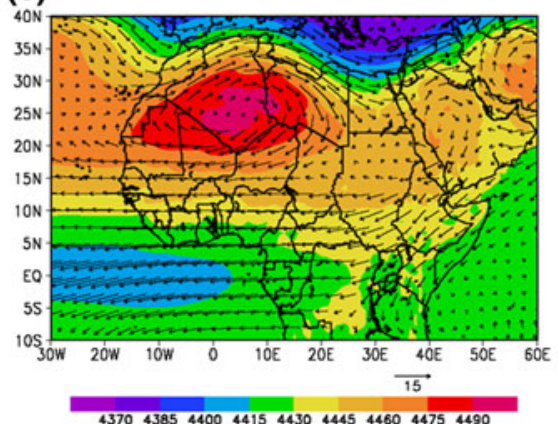

(c)

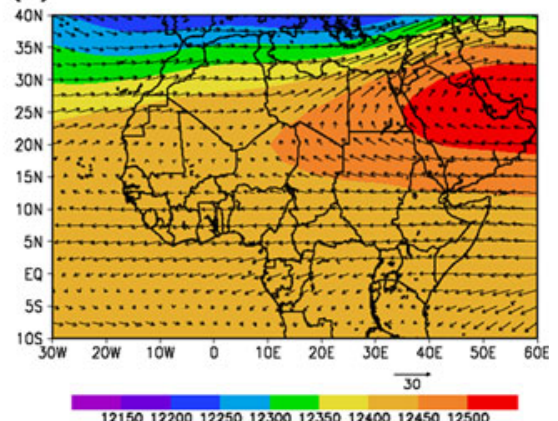

(f)

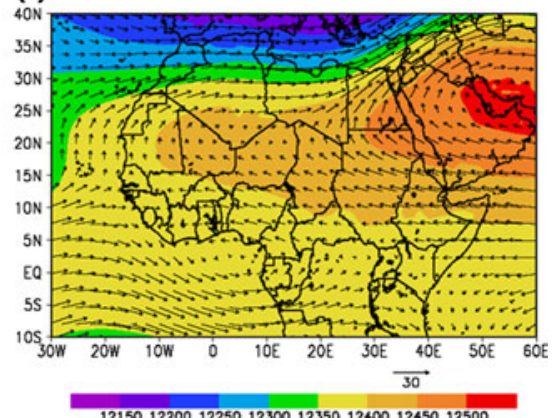

Fig. 7 Geopotential heights $(\mathrm{m})$ and wind vectors $(\mathrm{m} / \mathrm{s})$ averaged over June through September of 1981-2000 at a $925 \mathrm{hPa}, \mathbf{b} 600 \mathrm{hPa}$, and $\mathbf{c} 200 \mathrm{hPa}$ from the NCEP/NCAR reanalysis and at $\mathbf{d} 925 \mathrm{hPa}$, e
$600 \mathrm{hPa}$, and $\mathbf{f} 200 \mathrm{hPa}$ from the twentieth century RCM simulation. White regions are underground in the model simulations, while variables are interpolated through topography in the reanalysis (a)

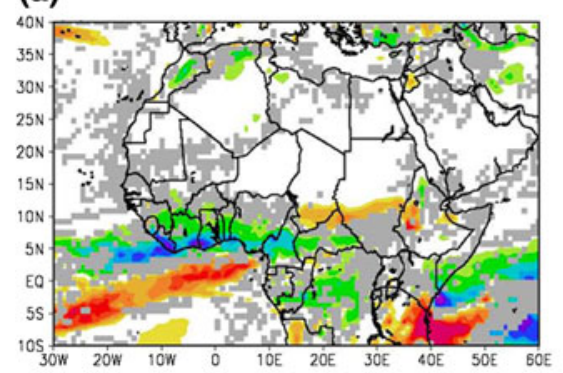

(d)

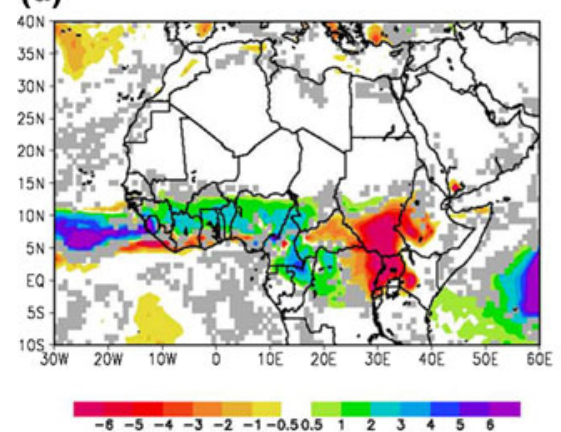

(b)

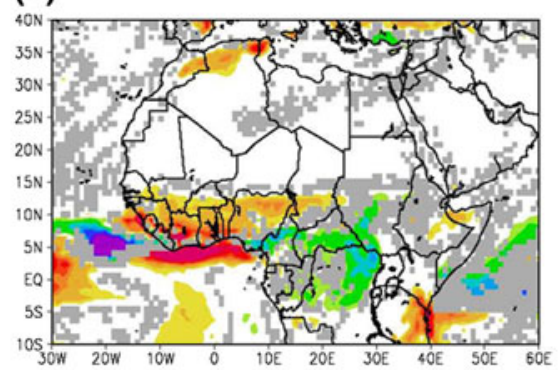

(e)

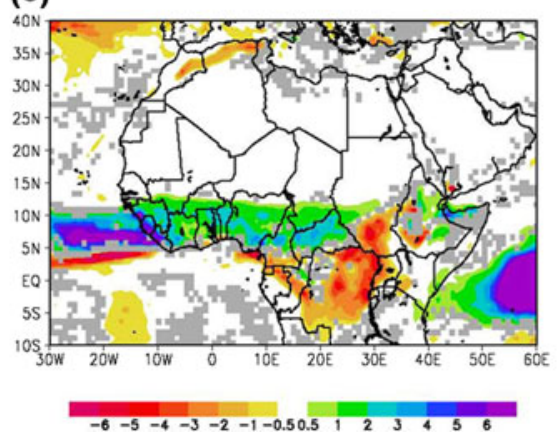

(c)

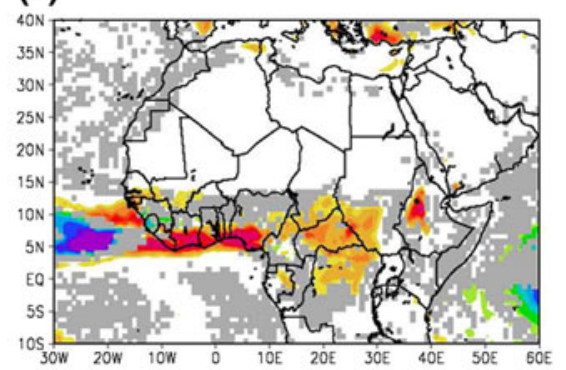

(f)

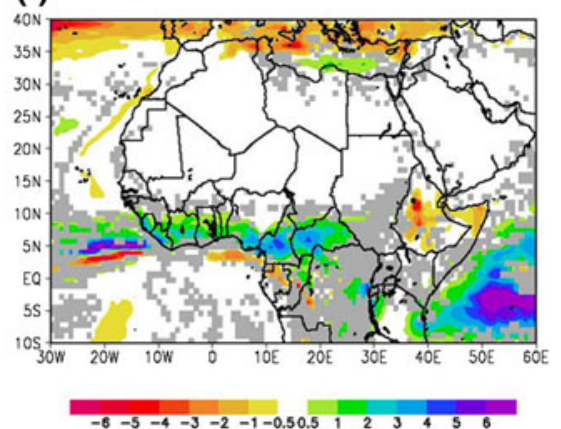

Fig. 8 Ensemble averaged monthly precipitation anomalies (twenty-first century-twentieth century) from the RCM simulations for a May, b June, c July, d August, e September, and f October. Units are $\mathrm{mm} /$ day. Areas where $<77 \%$ of the ensemble members agree are shaded gray 
(a)

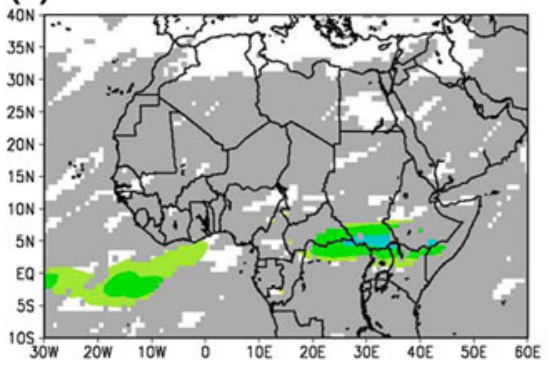

(d)

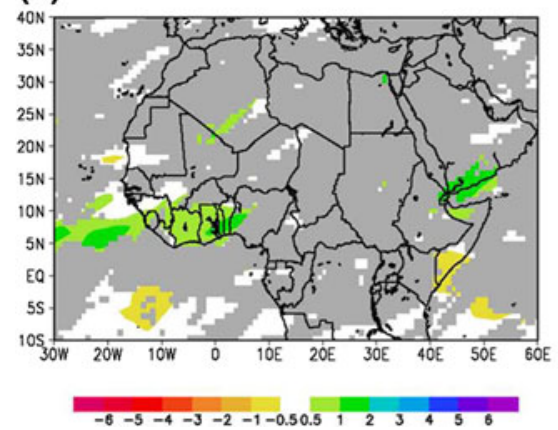

(b)

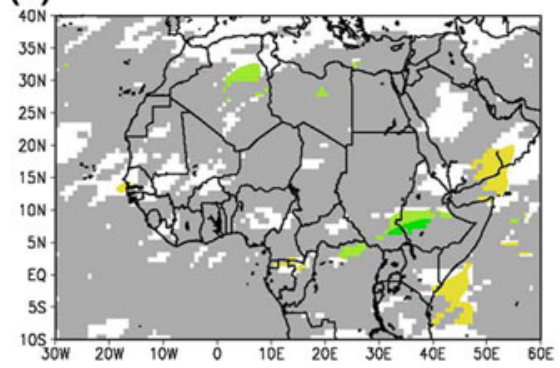

(e)

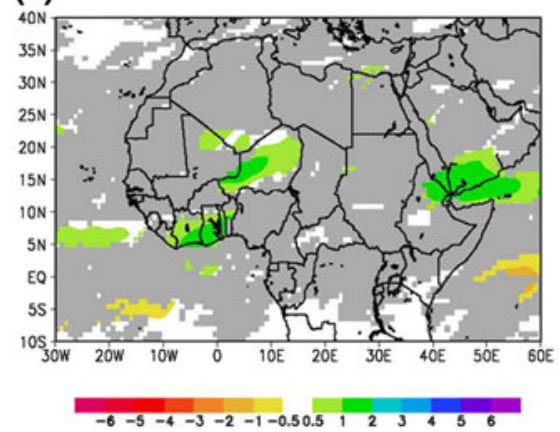

(c)

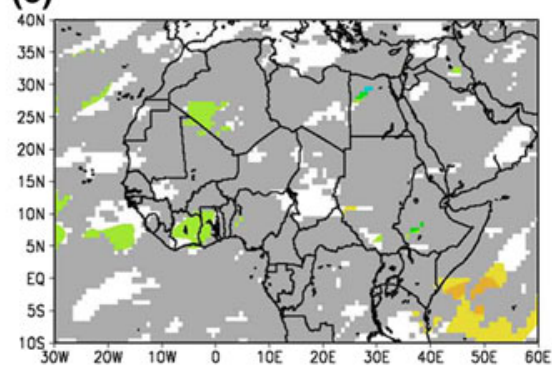

(f)

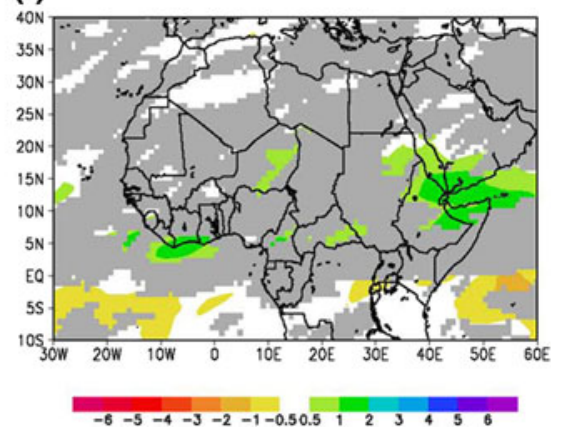

Fig. 9 Ensemble averaged monthly precipitation anomalies (twentyfirst century-twentieth century) from the nine IPCC AOGCM simulations used in this study (see text) for a May, b June, c July, d August, e September, and $\mathbf{f}$ October. Values are the difference

sign of the anomaly are shaded gray. Figure 8 is similar to Figure 3.3 of the IPCC AR4 Synthesis Report, but not directly comparable because the emissions scenario selected and months included in the averaging are different. Also the $77 \%$ criterion used here is stricter than the $66 \%$ criterion used in the IPCC report.

To allow for direct comparison between the results from the regional and global models, the monthly ensemble average precipitation anomalies derived from the nine AOGCM simulations used to produce the RCM ensemble are plotted in Fig. 9 in the same format as Fig. 8. Precipitation from each AOGCM is interpolated to the grid of the regional model. The precipitation anomalies plotted in Fig. 9 are quite similar to those from Figure 3.3 of the IPCC AR4, with inconsistent projections (gray shading) over nearly all of northern Africa. However, positive rainfall anomalies emerge over the Guinean Coast during July-September in Fig. 9, while the signal over that region is inconsistent in Figure 3.3 of the IPCC AR4. This may be due to the different emissions scenarios used.

It is evident by comparison of Figs. 8 and 9 that the ensemble members of the regional model show more consensus than the global models that provide surface and lateral boundary constraints for them. Wetter conditions simulated over central equatorial Africa during May and June in the AOGCMs (Fig. 9a) are not reproduced in the RCM simulations (Fig. 8a). During July the regional model between the 2081-2100 averaged monthly precipitation forced by the SRES A2 scenario minus the 1981-2000 averaged monthly means. Units are $\mathrm{mm} / \mathrm{day}$. Areas where $<77 \%$ of the ensemble members agree are shaded gray

produces drying along the Guinean Coast, while the AOGCMs project wetter conditions. In August and September the regional and global models both simulate wetter conditions at the end of the twenty-first century over parts of the Guinean Coast.

The RCM ensemble simulates a strong seasonality in the rainfall signal over northern Africa and the signal varies significantly by region (Fig. 8). To provide a measure of how extreme the twenty-first century anomalies are in comparison to twentieth century rainfall rates, the ensemble average twenty-first century precipitation is plotted in Fig. 10 as a percent of the simulated twentieth century rainfall rate. A value of 100 indicates that the twenty-first century and twentieth century rainfall rates are equal, whereas a value of 10 means that in the twenty-first century the rainfall rate is only $10 \%$ of its twentieth century value. Regions where $<0.25 \mathrm{~mm} /$ day of rainfall is received in the twentieth century simulation are shaded white to prevent misleading high percentages resulting from a very low value in the denominator.

In West Africa, including Senegal, Gambia, Guinea Bissau, Guinea, Sierra Leone, Liberia, Mali, Ivory Coast, Ghana, Burkina Faso, Togo, Benin, and Nigeria rainfall rates at the end of the twenty-first century are generally projected to increase during May by up to $6 \mathrm{~mm}$ /day along the coast and $2 \mathrm{~mm} /$ day inland (Fig. 8a) corresponding to about a $50 \%$ increase from the twentieth century rate 
(a)

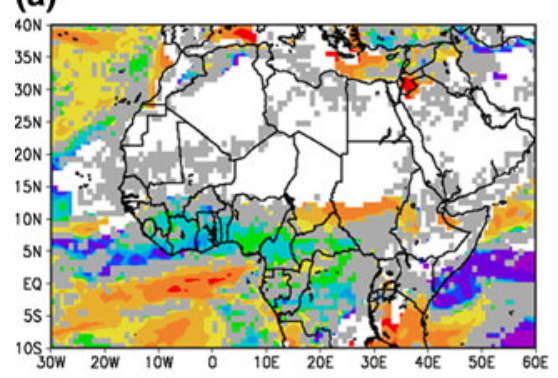

(d)

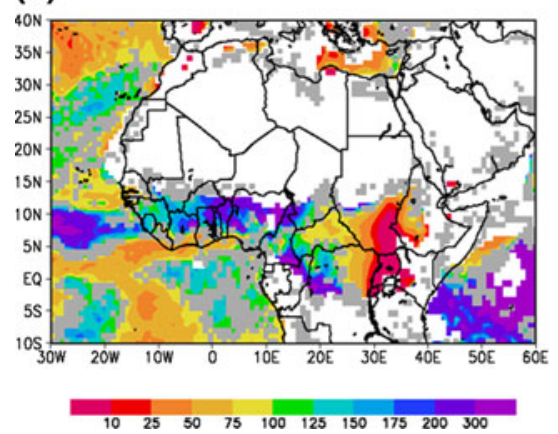

(b)

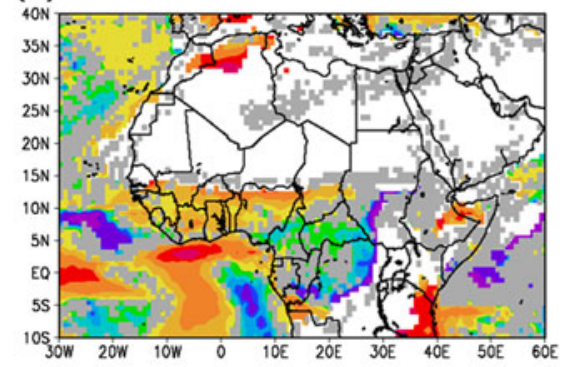

(e)

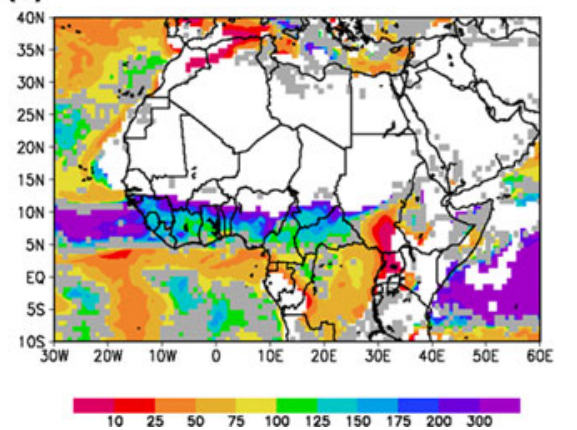

(c)

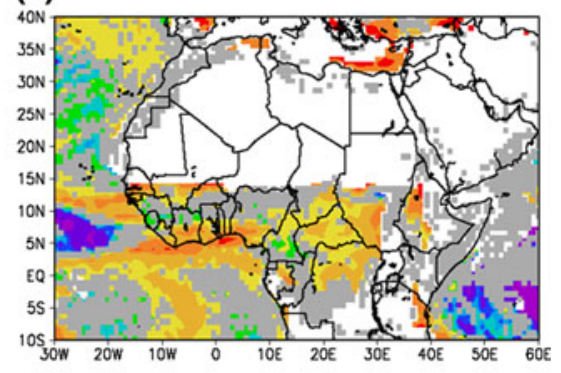

(f)

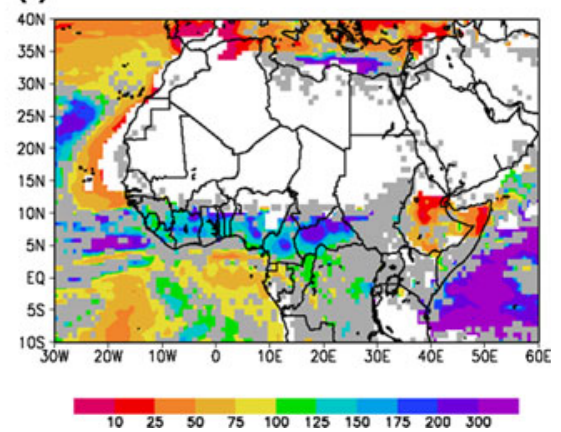

Fig. 10 Ensemble averaged twenty-first century precipitation rate as a percent of the twentieth century precipitation rate from the regional model simulations. The value 100 indicates the twenty-first century

(Fig. 10a). During June and July negative rainfall anomalies of up to $7 \mathrm{~mm} /$ day (Fig. 8b, c), or $50-75 \%$ (Fig. 10b, c) are simulated. In August, September, and October (Fig. 8d-f), wetter conditions, in some regions more than a doubling of rainfall, are simulated at the end of the twentyfirst century with the exception of drying over the Guinean Coast in August. No changes in rainfall are simulated over Niger and Mauritania where the twentieth century simulation produces conditions that are too dry. Since the regional model tends to simulate West African rainfall in a contracted band compared to the observations, it is possible that the twenty-first century rainfall anomalies simulated over the southern Sahel may apply to the northern Sahel as well.

Over the western part of North Africa, including Morocco, Algeria, and Tunisia, wetter (drier) conditions are projected over localized areas during May (June) (Fig. 8a, b). There is little change in July and August (Fig. 8c, d) and some drying in September and October (Fig. 8e, f). Over Western Sahara and the northeastern countries of Libya and Egypt both the twentieth and twenty-first century simulations produce no rainfall from May through October.

The precipitation projections vary regionally over Central Africa, including Chad, Sudan, Cameroon, Central African Republic, Democratic Republic of Congo, Congo, Gabon, and Equatorial Guinea. During May and June projections are generally wetter by about $1-2 \mathrm{~mm} /$ day and twentieth century precipitation rates are equal. Regions where the twentieth century monthly rainfall is $<0.25 \mathrm{~mm} /$ day are shaded white

representing about a 25\% increase from the twentieth century (Figs. 8a, b, 10a, b, respectively), except for a dry band over Chad in May and June and Sudan in May. During July conditions are projected to be drier by 2-4 mm/day (Fig. 8c) over many parts of Central Africa. In August and September (Fig. 8d, e) there is an east-west dipole, with wetter (drier) conditions in the western (eastern) part of Central Africa. Drying over southern Sudan is severe, with essentially no rainfall occurring in the twentyfirst century simulation (Fig. 10d, e). Generally wetter conditions or an inconsistent signal are simulated in October (Fig. 8f).

Over East Africa, including Eritrea, Ethiopia, Djibouti, Somalia, Uganda, Kenya, Rwanda, Burundi, and Tanzania, precipitation projections also vary regionally. Drier (wetter) conditions are projected over Tanzania and southern Kenya (southern Somalia) during May and June (Fig. 8a, b). Drying in Tanzania and Kenya is extreme (Fig. 10a, b). In July, August, and September (Fig. 10c-e) there is nearly complete drying in parts of Ethiopia, Kenya, Uganda, and Rwanda, with the greatest severity in August. Djibouti, the northern tip of Somalia, and parts of Ethiopia are projected to be wetter (drier) in September (October) (Fig. 10e, f).

Since changes in evaporation impact changes in water availability, precipitation minus evaporation anomalies are also evaluated. Monthly ensemble average twenty-first century minus twentieth century precipitation minus evaporation anomalies derived from the RCM (not shown) 
are similar to the precipitation anomalies (Fig. 8). Differences in evaporation (not shown) are opposite in sign, but smaller in magnitude than the precipitation anomalies. They are largest over West Africa during June through September where rates increase by up to $2 \mathrm{~mm} /$ day, and over eastern equatorial Africa in August and September where rates decrease by up to $5 \mathrm{~mm} /$ day. Comparison of the precipitation and precipitation minus evaporation anomalies demonstrates that the structure and sign of the precipitation minus evaporation projections are dominated by changes in precipitation, not evaporation.

Of great importance for impacts analysis are changes in extreme rainfall events. Based on the monthly precipitation anomalies (Fig. 8), West Africa emerges as a region that warrants further investigation of how the precipitation rates are distributed at the end of the twentyfirst century to assess flooding risk. Box plots are a useful way to display the distribution of a data set and show the minimum, first quartile, median, third quartile, maximum values, and outliers, which are defined here as values that exceed the third quartile value plus 1.5 times the innerquartile range or are less than the first quartile minus 1.5 times the innerquartile range. Box plots of 3-hourly landbased rainfall rates for the twentieth century and nine twenty-first century regional model simulations are shown for West Africa averaged over $18^{\circ} \mathrm{W}-18^{\circ} \mathrm{E}$ and $8-15^{\circ} \mathrm{N}$ (Fig. 11). The time period of analysis includes August 1 through September 30 and is chosen to isolate only the months during which rainfall is projected to increase in the twenty-first century.

In all of the twenty-first century simulations, the third quartile values exceed that of the twentieth century by at least $0.8 \mathrm{~mm} /$ day. In addition, simulated twenty-first

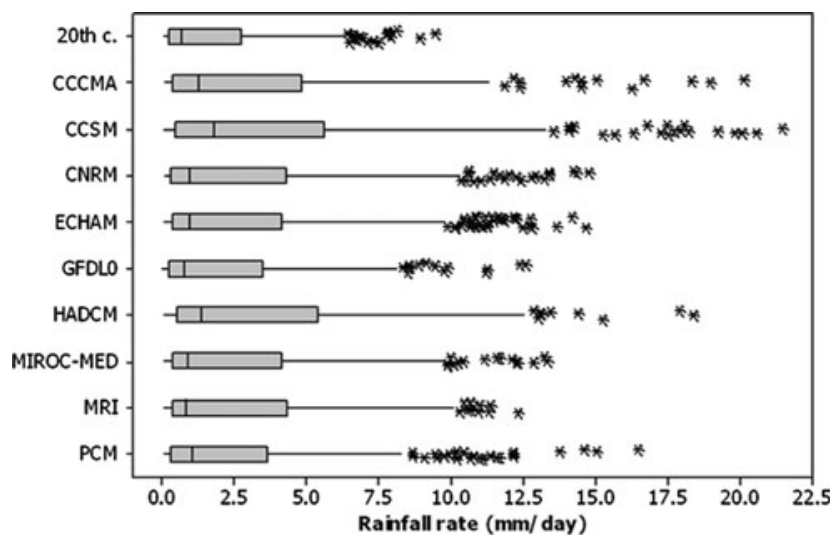

Fig. 11 Boxplots of 3-hourly land-based rainfall rates (mm/day) for the twentieth century and nine twenty-first century regional model simulations over West Africa covering $18^{\circ} \mathrm{W}-18^{\circ} \mathrm{E}$ and $8-15^{\circ} \mathrm{N}$ including events between August 1 through September 30. Outliers are denoted with stars offset to clarify overlapping marks century maximum rainfall rates are more intense than that of the twentieth century simulation, increasing to 12.3 $21.5 \mathrm{~mm} /$ day from $9.5 \mathrm{~mm} /$ day. The wetter conditions during August-September over West Africa are related to a higher frequency of more intense rainfall events, indicating the increased possibility for flooding during the twenty-first century over this region in the late summer.

\subsection{Near-surface air temperature and heat index}

The ensemble near-surface air temperature anomalies averaged from May through October simulated by the RCM and AOGCMs are shown in Fig. 12a, b, respectively, with Fig. 12b comparable to Figure 3.2 of the IPCC AR4. In contrast to the precipitation projections, there is a high level of agreement between the RCM and AOGCMs about the positive sign of projected near-surface air temperatures at the end of the twenty-first century. The RCM ensemble mean produces maximum warming of about $6 \mathrm{~K}$ over northwestern Africa (Fig. 12a), similar to that of the AOGCM mean (Fig. 12b). There is additional strong warming related to the July-August twenty-first century drought over the East African highlands in the RCM ensemble mean and a warming minimum over the central Sahara which are not produced by the AOGCM ensemble mean. A minimum in warming is simulated over the Guinean Coast and the coastal regions of the Horn of Africa by both the regional and global models. Despite the differences in the distribution, both modeling approaches produce an average warming between 3 and $6 \mathrm{~K}$ over of northern Africa.

A more detailed understanding of the warming is necessary to address the likelihood of additional heat waves in the future. Figure 13a and b display box plots of 3-hourly near-surface air temperatures over land during May 21August 21 from the twentieth century and twenty-first century simulations for the Sahel $\left(18^{\circ} \mathrm{W}-18^{\circ} \mathrm{E}\right.$ and $\left.8-15^{\circ} \mathrm{N}\right)$ and the Guinean Coast $\left(9^{\circ} \mathrm{W}-9^{\circ} \mathrm{E}\right.$ and $\left.4-7.5^{\circ} \mathrm{N}\right)$, respectively. As expected, all ensemble members simulate warming in the twenty-first century over both regions. Over the Sahel region the median surface air temperature warms by $3.2-5.4 \mathrm{~K}$ (with a median of $4.0 \mathrm{~K}$ ), from $301.6 \mathrm{~K}$ in the twentieth century to $304.8-307.1 \mathrm{~K}$ in the future. Since the distribution of temperature is shifted to the right, values which were extreme in the twentieth century occur more often in the twenty-first century. Eight of the nine RCM ensemble members simulate a median air temperature that exceeds the third quartile of the twentieth century simulation, and the maximum temperature rises from $310.2 \mathrm{~K}$ in the twentieth century to $312.9-314.6 \mathrm{~K}$ in the twenty-first century. It is clear from these changes in the temperature distribution that extreme high temperatures will occur more commonly in the twenty-first century, increasing the 
(a)

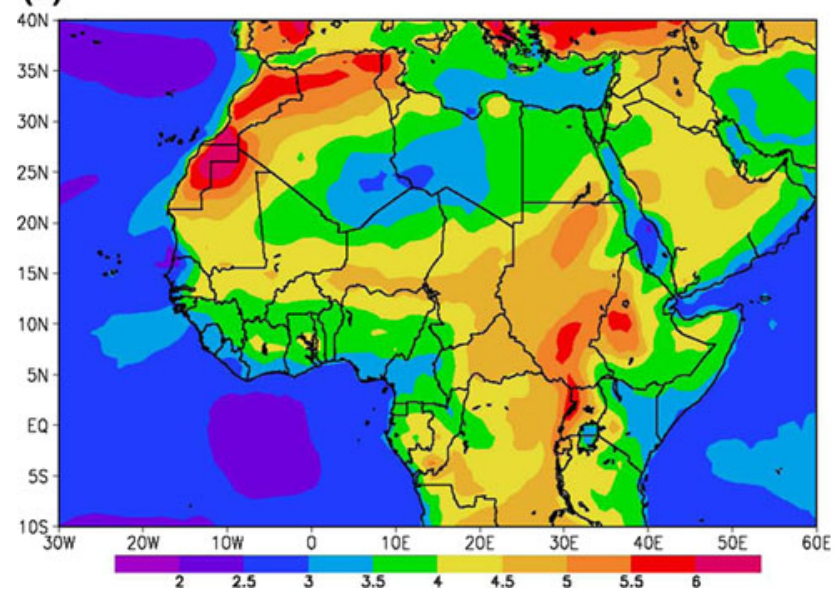

(b)

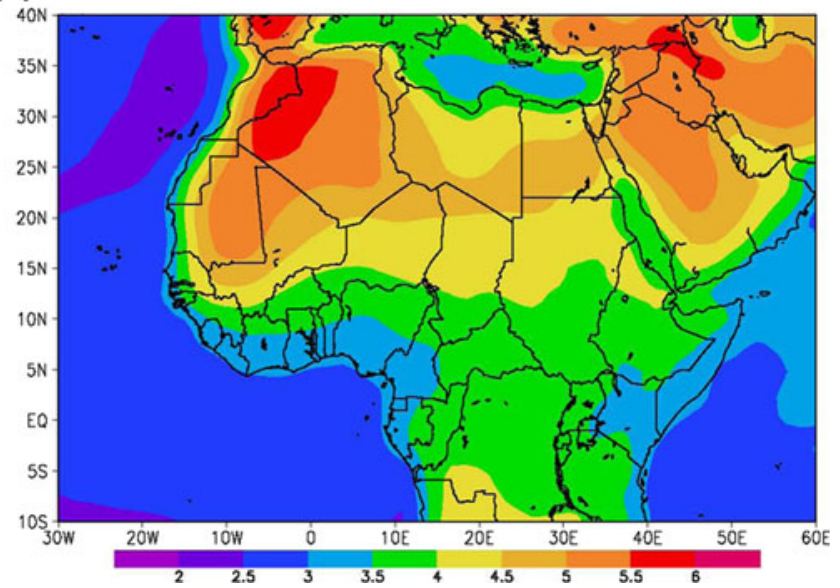

Fig. 12 Ensemble averaged May-October near-surface air temperature (K) twenty-first century-twentieth century anomalies from a RCM and b AOGCM simulations
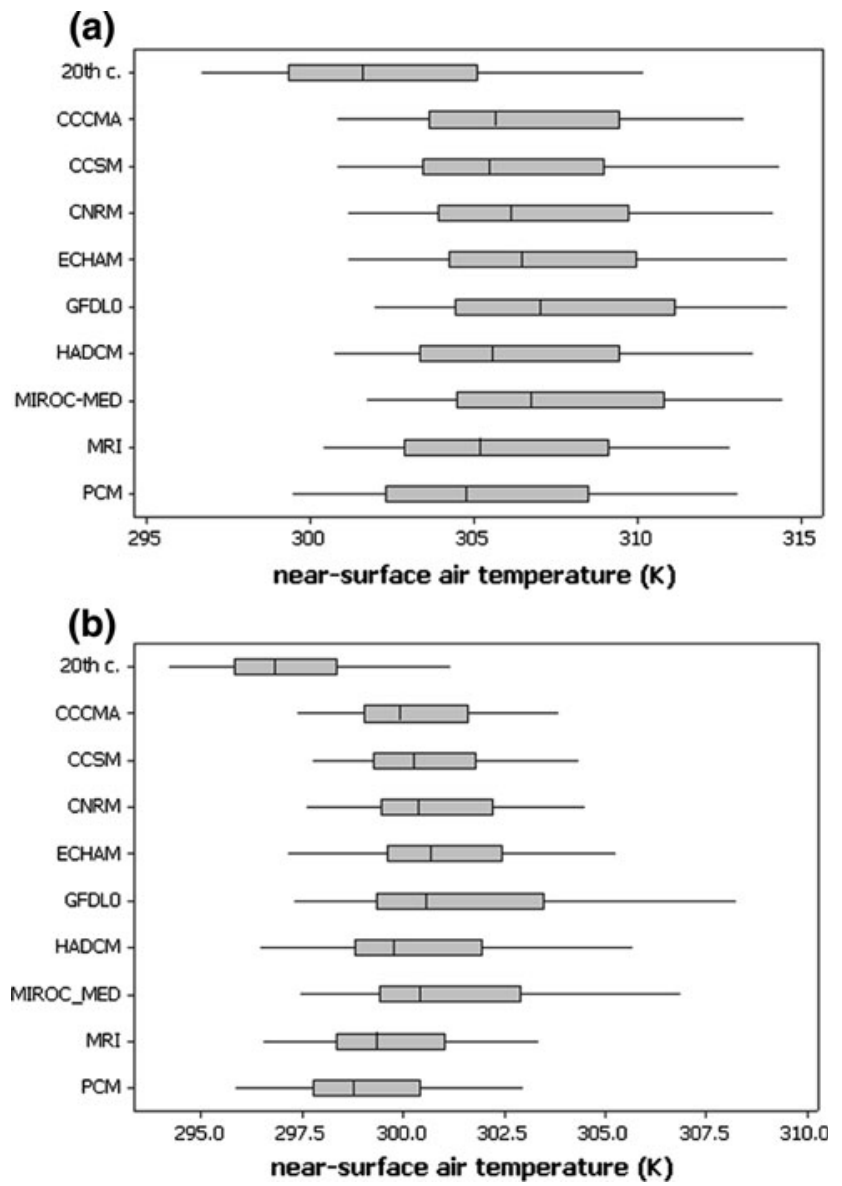

Fig. 13 Boxplots of 3-hourly land-based near-surface air temperature (K) from May 21 to August 21 for the twentieth century and nine twenty-first century RCM simulations for a the Sahel region averaged over $18^{\circ} \mathrm{W}-18^{\circ} \mathrm{E}$ and $8-15^{\circ} \mathrm{N}$ and $\mathbf{b}$ the Guinean Coast region averaged over $9^{\circ} \mathrm{W}-9^{\circ} \mathrm{E}$ and $4-7.5^{\circ} \mathrm{N}$ likelihood for longer and more intense heat waves over the Sahel region.

Over the Guinean Coast region (Fig. 13b), warming is more moderate, with a median near-surface air temperature of $296.8 \mathrm{~K}$ in the twentieth century and a range of $298.8_{-}$ $300.7 \mathrm{~K}$ in the twenty-first century, representing an increase of 2.0-3.8 K with a median of 3.4 K. Again higher temperatures occur more frequently, with the median of all nine twenty-first century RCM ensemble members exceeding the third quartile of the twentieth century simulation. Maximum temperatures rise by $1.8-7.1 \mathrm{~K}$, from $301.2 \mathrm{~K}$ in the twentieth century to $303.0-308.3 \mathrm{~K}$ in the twenty-first century.

These temperature changes are accompanied by changes in relative humidity, and both are significant for understanding impacts on human health due to heat exposure (Steadman 1979). The heat index is a convenient way to represent the combination of changes in these two factors for human comfort and health. Although perceived temperature is also affected by wind speed, atmospheric pressure, and solar radiation, it is a good assumption that changes in temperature and humidity are the most important. The heat index defined by Steadman (1979) follows the equation:

$$
\begin{aligned}
\mathrm{HI} & =-42.4+2.05(T)+10.1(R) \\
& -0.225(T R)-6.84\left(10^{-3}\right)\left(T^{2}\right) \\
& -5.48\left(10^{-2}\right)\left(R^{2}\right)+1.23\left(10^{-3}\right)\left(T^{2} R\right) \\
& +8.53\left(10^{-4}\right)\left(T R^{2}\right)-1.99\left(10^{-6}\right)\left(T^{2} R^{2}\right)
\end{aligned}
$$

where $\mathrm{HI}$ is the heat index $\left({ }^{\circ} \mathrm{F}\right), T$ the air temperature $\left({ }^{\circ} \mathrm{F}\right)$, and $R$ is the relative humidity in percent. Steadman (1979) 
developed this heat index for temperatures above $80^{\circ} \mathrm{F}$ $(300 \mathrm{~K})$, which is generally the case over northern Africa in summer. He included a condition for relative humidities above $40 \%$, and this is also generally satisfied in summer except over the Sahara, where the low humidity results in a perceived temperature that is cooler than the actual air temperature. A heat index between 80 and $90^{\circ} \mathrm{F}$ (300-305 K) indicates a possibility of fatigue related to prolonged exposure to the sun and physical activity. Sunstroke, a serious life threatening condition, and heat cramps are possible for a heat index of $90-105^{\circ} \mathrm{F}(305-314 \mathrm{~K})$ and likely for a heat index of $105-130^{\circ} \mathrm{F}(314-326 \mathrm{~K})$. Sunstroke is very likely for a heat index that exceeds $130^{\circ} \mathrm{F}$ (326 K). For conciseness, the heat index categories 300$305,305-314,314-326$, and over $326 \mathrm{~K}$ will be referred to as low, medium, high, and severe risks, respectively.

We calculate the maximum heat index for each day between May 1 and October 31 occurring between $09 \mathrm{Z}$ and $15 \mathrm{Z}$, the period when maximum air temperatures are probable over northern Africa. Figure 14a-c show the number of times the worst daily heat index reaches the low, medium, and high risk categories during the May-October period in the twentieth century RCM simulation, respectively, and Fig. 14d-f are the same for the twenty-first century heat indices. (The number of days in the severe heat index category is not plotted because this threshold is not exceeded in any simulation.)

In the twentieth century simulation, the Guinean Coast region experiences around 120 low-risk days, 0-40 medium-risk days, and no high-risk days (Fig. 14a-c, respectively). In the twenty-first century simulations, the medium- and high-risk heat indices (Fig. 14e, f) occur more frequently at the expense of low-risk events (Fig. 14d). Similarly, over the Sahel higher risk heat indices occur more frequently, with up to 180 days of medium risk (Fig. 14b) and no high-risk days (Fig. 14c) in the twentieth century, and up to 160 high-risk days in the twenty-first century (Fig. 14f). At the end of the twentyfirst century people in the Sahel region are projected to experience the most severe increases in sun stroke and heat cramps.

In East Africa over Somalia, the number of medium-risk days increases from around 40 in the twentieth century (Fig. 14b) to over 160 in the twenty-first century (Fig. 14e). Ethiopia becomes more susceptible to low-risk heat indices in the twenty-first century (Fig. 14a, d). Over Central Africa, medium-risk days become more prevalent (Fig. 14b, e) and high-risk days increase from zero in the twentieth century (Fig. 14c) to up to 100 in the twenty-first century (Fig. 14f). (a)

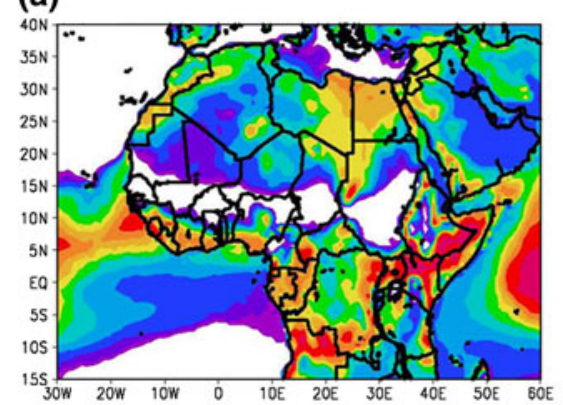

(d)

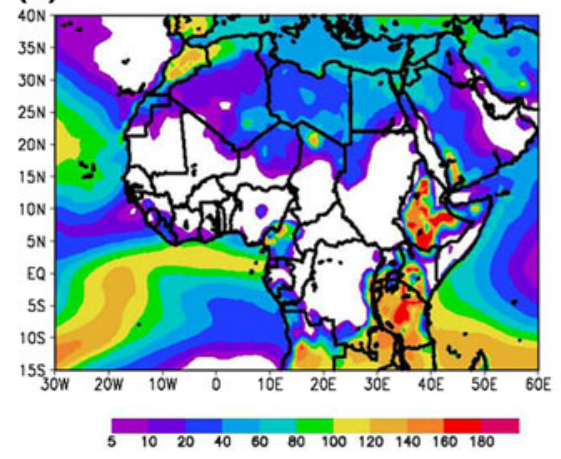

(b)

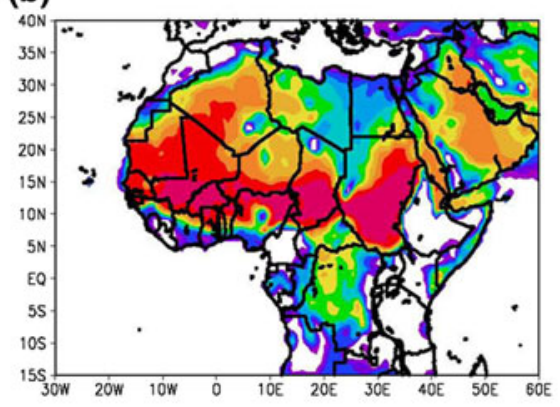

(e)

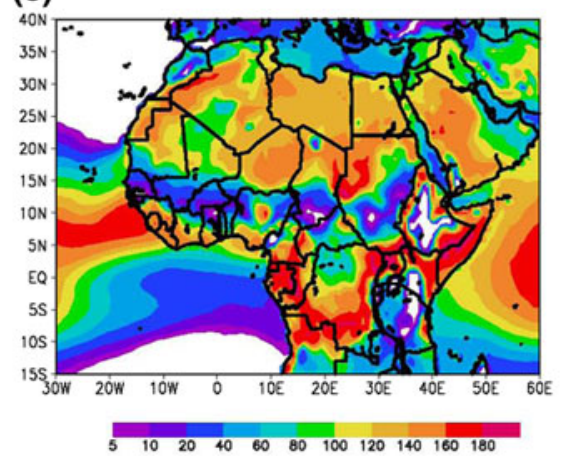

(c)

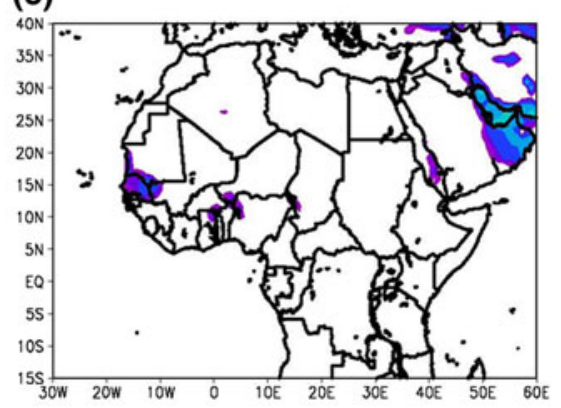

(f)

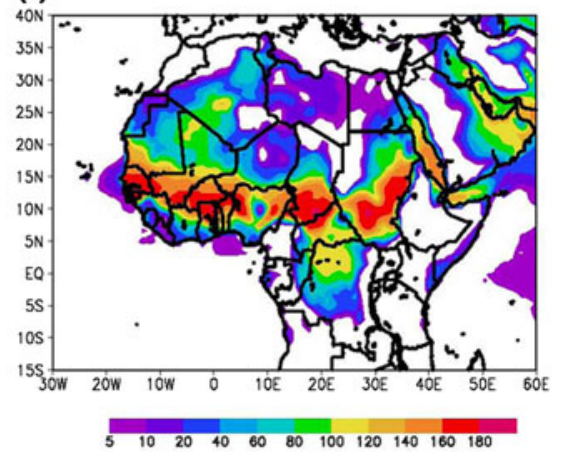

Fig. 14 The number of days between May 1 and October 31 during which the maximum heat index occurring between $09 \mathrm{Z}$ and $15 \mathrm{Z}$ is in a low, $\mathbf{b}$ medium, and $\mathbf{c}$ high risk category in the twentieth century simulation, and the twenty-first century ensemble average number of days between May 1 and October 31 during which the maximum heat index occurring between $09 \mathrm{Z}$ and $15 \mathrm{Z}$ is in $\mathbf{d}$ low, e medium, and $\mathbf{f}$ high risk category 


\section{Conclusions}

A method for predicting future climate that utilizes both regional and global models is developed and applied to project climate change during this century over northern Africa. The regional model offers the fine horizontal resolution appropriate for capturing climate processes accurately and providing information on space scales appropriate for impacts analysis. Selecting a set of parameterizations and a land-surface model that are optimal for simulation of northern African climate improves the simulation. Output from present day and future simulations from AOGCMs, which were produced for the IPCC AR4, provides anomalies in future SST and global connectivity. This method is not to be confused with traditional dynamical downscaling, which applies boundary conditions to a regional model directly. Boundary conditions for the regional model are derived from monthly mean AOGCM output to maintain information about the seasonal cycle, but to remove synoptic and diurnal effects. Similar to other studies, testing shows that the influence of prescribing transients in the lateral boundary conditions is small on the tropical domain, validating this choice for climate simulation.

An ensemble approach is taken to provide different realizations of future climate in the regional model. The atmospheric $\mathrm{CO}_{2}$ concentration is increased to $757 \mathrm{ppmv}$, which is the mean value for 2081-2100 according to the IPCC's SRESA2 emissions scenario. A nine-member ensemble representing northern African climate for 20812100 is created by adding SST and lateral boundary condition anomalies from nine different AOGCM simulations to the present day boundary conditions. A benefit of this method is that there is only one control simulation, and nine twenty-first century simulations. If we were to use nine twentieth century simulations with nine twenty-first century simulations with lateral boundary conditions provided directly from the AOGCMs, it would be unclear how much the quality of the control simulations impacts a climate change response. In addition, this method produces a relatively accurate control simulation of the northern Africa climate.

Agreement among the nine ensembles leads to a robust results. Over vast regions of northern Africa in summer, the regional model ensemble members produce agreement among at least seven of the nine realizations $(77 \%$ or more). This level of agreement is much stronger than that of the AOGCMs used for the anomalous lateral boundary and SST constraints. Although the AOGCMs show little consensus in their predictions of West African rainfall at the end of the twenty-first century, it is worthwhile to note that with the exception of two outliers (one very wet and the other very dry), the models generally predict West
African annual rainfall changes that are within $\pm 0.5 \mathrm{~mm} /$ day. The regional model produces rainfall anomalies within this range between May and October. It may be that in the future annual rainfall changes over West Africa are near zero while, as simulated by the regional model, changes in the seasonal cycle are considerable.

Projections from the regional model are presented with focus on the climate change parameters most relevant for human impacts, and include the following:

- Over West Africa, including Senegal, Gambia, Guinea Bissau, Guinea, Sierra Leone, Liberia, Mali, Ivory Coast, Ghana, Burkina Faso, Togo, Benin, and Nigeria wetter conditions are projected during the month of May, with some regions receiving up to $50 \%$ more rainfall in the twenty-first century compared with the twentieth century. A mid-summer drought during June and July develops in this region late in the twenty-first century, with only half of the twentieth century rainfall delivered. Wetter conditions resume during August through October, with the exception of the Guinean Coast during August. During these months in the twenty-first century simulations there is an increase in intense rainfall events and the likelihood of flooding in the late-summer.

- Over Central Africa, the regional model projects increases in rainfall during May and June over Cameroon, Central African Republic, Congo, and Democratic Republic of Congo with drying over Chad and Sudan and drier conditions in July. In August severe drying with $<10 \%$ of the twentieth century rainfall covers southern Sudan, northern Democratic Republic of Congo, and in East Africa, Uganda, Rwanda, Kenya and western Ethiopia. Drying continues into September except over Central Africa Republic, where conditions are wetter in October.

- Generally in the twenty-first century there is an increase in the heat index over all of northern Africa throughout May-October. It is expected that the people in the Sahel region will be the most vulnerable, experiencing up to 160 days per year in the twentyfirst century with a likely chance of heat stroke. At the next highest risk are the people of central equatorial Africa, Somalia, Kenya, Uganda, Gabon, and the Guinean Coast.

The RCM ensemble method produces precipitation projections for the end of the twenty-first century over northern Africa that are very consistent across the ensemble members. This is despite the fact that the AOGCMs which provide the lateral and surface boundary condition anomalies produce different projections themselves and inspires the question, why are the regional model ensemble members consistent when the global models are not? In the 
context of the current understanding of West African climate, we may expect SST warming in the twenty-first century to play a large, even dominant, role in determining the rainfall projections. However, the nine regional model simulations which are constrained with nine different twenty-first century SST distributions produce similar precipitation anomalies. This may be indicating that some other factors are more important in forcing centennial-scale climate change than SSTs in the future, or that the details of the SST increases are not as important as the fact that they are all warming.

A better physical understanding of physical processes of change and the role of the various twenty-first century forcings, including SSTs, greenhouse gasses, and remote forcings, as well as the sensitivity to soil moisture initialization, on northern African rainfall also will support confidence in the results. Regional model simulations with twenty-first century $\mathrm{CO}_{2}$ forcing alone, twenty-first century SSTA constraints alone, and idealized SSTAs will be analyzed in another paper to address these issues and understand the physical processes that support the changes reported here as well as the high level of consistency of the regional model ensembles. A dynamical analysis of the twenty-first century northern African circulation will also be presented.

The potential for continued improvement in this methodology is recognized. Including reliable interactive vegetation and dust models may reduce uncertainty, as well as broadening the ensemble to include additional members. Creating ensembles by including other regional models would be a valuable contribution to this method. Additionally, it may be advantageous to utilize simulations with other sets of land-surface models and parameterizations if the quality of the control simulation can be preserved. Forcing the regional model with greenhouse gas concentrations from other emissions scenarios would also be useful. Finally, long simulations instead of climate snapshots would be useful to better understand changes in interannual variability.

Acknowledgments Financial support was provided by National Science Foundation Award ATM-0415481. We are grateful to the National Center for Atmospheric Research supercomputer facility, on which the simulations were run, and to the Program for Climate Model Diagnosis and Intercomparison, which has formed and maintained an archive of the IPCC AR4 AOGCM simulations. We wish to thank two anonymous reviewers for their constructive comments. We are also grateful to the other members of our research group, Ned Vizy, Emily Riddle, and Bing Pu, for their useful comments and encouragement throughout the course of this project.

Open Access This article is distributed under the terms of the Creative Commons Attribution Noncommercial License which permits any noncommercial use, distribution, and reproduction in any medium, provided the original author(s) and source are credited.

\section{References}

Adler RF et al (2003) The version 2 Global Precipitation Climatology Project (GPCP) monthly precipitation analysis (1979-present). J Hydrometeorol 4:1147-1167. doi:10.1175/1525-7541(2003) 004<1147:TVGPCP $>2.0$.CO;2

Betts AK (1986) A new convective adjustment scheme. Part I: observational and theoretical basis. Q J R Meteorol Soc 112:677-691

Betts AK, Miller MJ (1986) A new convective adjustment scheme. Part II: single column tests using GATE wave, BOMEX, and Arctic air-mass data sets. Q J R Meteorol Soc 112:693-709

Biasutti M, Held IM, Sobel AH, Giannini A (2008) SST forcings and Sahel rainfall variability in simulations of the twentieth and twenty-first centuries. J Clim 21(14):3471-3486. doi:10.1175/ 2007JCLI1896.1

Caminade C, Terray L, Maisonnave E (2006) West African monsoon response to greenhouse gas and sulphate aerosol forcing under two emission scenarios. Clim Dyn 26:531-547. doi:10.1007/ s00382-005-0083-7

Chen F, Dudhia J (2001) Coupling an advanced land-surface/ hydrology model with the Penn State/NCAR MM5 modeling system. Part I: model description and implementation. Mon Weather Rev 129:569-585. doi:10.1175/1520-0493(2001)129 $<0569$ :CAALSH $>2.0 . \mathrm{CO} ; 2$

Chen SH, Sun WY (2002) A one-dimensional time dependent cloud model. J Meteorol Soc Jpn 80:99-118. doi:10.2151/jmsj.80.99

Cook KH (1999) Generation of the African Easterly Jet and its role in determining West African precipitation. J Clim 12(5):1165-1184. doi:10.1175/1520-0442(1999)012<1165:GOTAEJ $>2.0 . C O ; 2$

Cook KH (2008) Climate science: the mysteries of Sahel droughts. Nat Geosci 1(10):647-648. doi:10.1038/ngeo320

Cook KH, Vizy EK (2006a) Coupled model simulations of the West African monsoon system: 20th century simulations and 21st century predictions. J Clim 19:3681-3703. doi:10.1175/JCLI 3814.1

Cook KH, Vizy EK (2006b) South American climate during the Last Glacial Maximum: delayed onset of the South American monsoon. J Geophys Res 111. doi:10.1029/2005JD005980

Cook KH, Vizy EK (2008) Effects of twenty-first-century climate change on the Amazon rain forest. J Clim 21:542-560. doi: 10.1175/2007JCLI1838.1

Doherty R, Kutzbach J, Foley J, Pollard D (2000) Fully coupled climate/dynamical vegetation model simulations over Northern Africa during the mid-Holocene. Clim Dyn 16(8):561-573. doi: $10.1007 / \mathrm{s} 003820000065$

Dudhia J (1989) Numerical study of convection observed during the winter monsoon experiment using a mesoscale two-dimensional model. J Atmos Sci 46:3077-3107. doi:10.1175/1520-0469 (1989)046<3077:NSOCOD>2.0.CO;2

European Centre for Medium-Range Weather Forecasts (2002) The ERA-40 archive. ECMWF, Reading, p 40

Folland C, Owen J, Ward MN, Colman A (1991) Prediction of seasonal rainfall in the Sahel region using empirical and dynamic methods. J Forecast 10(1-2):21-56. doi:10.1002/for. 3980100104

Giannini A, Saravanan R, Chang P (2003) Oceanic forcing of Sahel rainfall on interannual to interdecadal time scales. Science 302(5647):1027-1030. doi:10.1126/science. 1089357

Grodsky SA, Carton JA, Nigam S (2003) Near surface westerly wind jet in the Atlantic ITCZ. Geophys Res Lett 30(19). doi: 10.1029/2003GL017867

Hagos SM, Cook KH (2007) Dynamics of the West African monsoon jump. J Clim 20(21):5264-5284. doi:10.1175/2007JCLI1533.1 
Hagos SM, Cook KH (2008) Ocean warming and late-twentiethcentury Sahel drought and recovery. J Clim 21(15):3797-3814. doi:10.1175/2008JCLI2055.1

Hoerling M, Hurrell J, Eischeid J, Phillips A (2006) Detection and attribution of twentieth-century northern and southern African rainfall change. J Clim 19(16):3989-4008. doi:10.1175/ JCLI3842.1

Hong S, Noh Y, Dudhia J (2006) A new vertical diffusion package with an explicit treatment of entrainment processes. Mon Weather Rev (134):2318-2341. doi:10.1175/MWR3199.1

Hsieh JS, Cook KH (2005) Generation of African easterly wave disturbances: Relationship to the African easterly jet. Mon Weather Rev 133(5):1311-1327. doi:10.1175/MWR2916.1

Hsieh JS, Cook KH (2007) A study of the energetics of African easterly waves using a regional climate model. J Atmos Sci 64(2):421-440. doi:10.1175/JAS3851.1

Hsieh JS, Cook KH (2008) On the instability of the African easterly jet and the generation of African waves: reversals of the potential vorticity gradient. J Atmos Sci 65(7):2130-2151. doi:10.1175/ 2007JAS2552.1

IPCC (2007) Climate change 2007: impacts, adaptation and vulnerability. In: Parry ML, Canziani OF, Palutikof JP, van der Linden PJ, Hanson CE (eds) Contribution of working group II to the fourth assessment report of the intergovernmental panel on climate change. Cambridge University Press, Cambridge, p 976

Janjic ZI (1990) The step-mountain coordinate: physical package. Mon Weather Rev 118:1429-1443. doi:10.1175/1520-0493 (1990) $118<1429$ :TSMCPP $>2.0$. CO;2

Janjic ZI (1994) The step-mountain Eta coordinate model: further developments of the convection, viscous sublayer and turbulence closure schemes. Mon Weather Rev 122:927-945. doi: 10.1175/1520-0493(1994)122<0927:TSMECM>2.0.CO;2

Janjic ZI (1996) The surface layer in the NCEP Eta Model. In: Eleventh conference on numerical weather prediction, Norfolk, VA, 19-23 August 1996. Amer Meteor Soc, Boston, MA, pp 354-355

Janjic ZI (2000) Comments on "development and evaluation of a convection scheme for use in climate models". J Atmos Sci 57:3686. doi:10.1175/1520-0469(2000)057<3686:CODAEO> 2.0.CO;2

Janjic ZI (2002) Nonsingular implementation of the Mellor-Yamada Level 2.5 Scheme in the NCEP Meso model. NCEP Office Note No. 437, $61 \mathrm{pp}$

Joly M, Voldoire A, Douville H, Terray P, Royer JF (2007) African monsoon teleconnections with tropical SSTs: validation and evolution in a set of IPCC4 simulations. Clim Dyn 29(1):1-20. doi:10.1007/s00382-006-0215-8

Kain JS, Fritsch JM (1990) A one-dimensional entraining detraining plume model and its application in convective parameterization. J Atmos Sci 47(23):2784-2802. doi:10.1175/1520-0469(1990) 047<2784:AODEPM>2.0.CO;2

Kain JS, Fritsch JM (1993) Convective parameterization for mesoscale models: the Kain-Fritcsh scheme. The representation of cumulus convection in numerical models. Meteor Monogr 24:165-170

Kalnay E et al (1996) The NCEP/NCAR 40-Year Reanalysis Project. Bull Am Meteorol Soc 77:437-471. doi:10.1175/1520-0477 (1996)077<0437:TNYRP>2.0.CO;2

Koster RD et al (2004) Regions of strong coupling between soil moisture and precipitation. Science 305(5687):1138-1140. doi: 10.1126/science. 1100217

Lamb PJ (1978) Case studies of Tropical Atlantic surface circulation patterns during recent sub-Saharan weather anomalies: 1967 and 1968. Mon Weather Rev 106:482-491. doi:10.1175/1520-0493 (1978) $106<0482$ :CSOTAS $>2.0 . C O ; 2$
Lin YL, Farley RD, Orville HD (1983) Bulk parameterization of the snow field in a cloud model. J Appl Meteorol 22:1065-1092. doi: 10.1175/1520-0450(1983)022<1065:BPOTSF $>2.0 . C O ; 2$

Liu Z, Wang Y, Glallimore R, Notaro M, Prentice IC (2006) On the cause of abrupt vegetation collapse in North Africa during the Holocene: climate variability vs. vegetation feedback. Geophys Res Lett 33. doi:10.1029/2006GL028062

Meehl GA, Covey C, Delworth T, Latif M, McAvaney B, Mitchell JFB, Stouffer RJ, Taylor KE (2007) The WCRP CMIP3 multimodel dataset: a new era in climate change research. Bull Am Meteorol Soc 88:1383-1394. doi:10.1175/BAMS-88-9-1383

Mellor GL, Yamada T (1982) Development of a turbulence closure model for geophysical fluid problems. Rev Geophys 20:851875. doi:10.1029/RG020i004p00851

Mlawer EJ, Taubman SJ, Brown PD, Iacono MJ, Clough SA (1997) Radiative transfer for inhomogeneous atmosphere: RRTM, a validated correlated-k model for the longwave. J Geophys Res 102(D14):16663-16682. doi:10.1029/97JD00237

Monin AS, Obukhov AM (1954) Basic laws of turbulent mixing in the surface layer of the atmosphere. Contrib Geophys Inst Acad Sci USSR 151:163-187 (in Russian)

New M, Hulme M, Jones P (1999) Representing twentieth century space-time climate variability. Part I: development of a 19611990 mean monthly terrestrial climatology. J Clim 12:829-856. doi:10.1175/1520-0442(1999)012<0829:RTCSTC >2.0.CO;2

Paeth H, Thamm HP (2007) Regional modelling of future African climate north of 15 degrees $\mathrm{S}$ including greenhouse warming and land degradation. Clim Change 83(3):401-427. doi:10.1007/ s10584-006-9235-y

Paeth H, Born K, Girmes R, Podzun R, Jacob D (2009) Regional climate change in tropical and northern Africa due to greenhouse forcing and land use changes. J Cilm 22(1):114-132. doi: 10.1175/2008JCLI2390.1

Patricola CM, Cook KH (2007) Dynamics of the West African monsoon under mid-Holocene precessional forcing: regional climate model simulations. J Clim 20(4):694-716. doi:10.1175/ JCLI4013.1

Patricola CM, Cook KH (2008) Atmosphere/vegetation feedbacks: A mechanism for abrupt climate change over northern Africa. J Geophys Res 113. doi:10.1029/2007JD009608

Rojas M, Seth A (2003) Simulation and sensitivity in a nested modeling study for South America. Part II. GCM boundary forcing. J Clim 16:2454-2471. doi:10.1175/1520-0442(2003) $016<2454$ :SASIAN $>2.0$. CO; 2

Rutledge SA, Hobbs PV (1984) The mesoscale and microscale structure and organization of clouds and precipitation in midlatitude cyclones. XII: a diagnostic modeling study of precipitation development in narrow cold-frontal rainbands. J Atmos Sci 41(20):2949-2972. doi:10.1175/1520-0469(1984) 041<2949:TMAMSA>2.0.CO;2

Seth A, Rojas M (2003) Simulation and sensitivity in a nested modeling study for South America. Part I. Reanalysis boundary forcing. J Clim 16:2437-2453. doi:10.1175/1520-0442(2003) $016<2437$ :SASIAN $>2.0 . \mathrm{CO} ; 2$

Skamarock WC, Klemp JB, Dudhia J, Gill DO, Barker DM, Wang W, Powers JG (2005) A description of the Advanced Research WRF Version 2. NCAR Tech. Note, ncar/TN-468+STR, 88 pp

Smirnova TG, Brown JM, Benjamin SG (1997) Performance of different soil model configurations in simulating ground surface temperature and surface fluxes. Mon Weather Rev 125:18701884. doi:10.1175/1520-0493(1997)125<1870:PODSMC $>2.0$. $\mathrm{CO} ; 2$

Smirnova TG, Brown JM, Benjamin SG, Kim D (2000) Parameterization of cold season processes in the MAPS land-surface scheme. J Geophys Res 105:4077-4086. doi:10.1029/ 1999JD901047 
Steadman RG (1979) The assessment of sultriness. Part I: a temperature-humidity index based on human physiology and clothing science. J Appl Metab 18(7):861-873. doi:10.1175/ 1520-0450(1979)018<0861:TAOSPI >2.0.CO;2

Tao WK, Simpson J, McCumber M (1989) An ice-water saturation adjustment. Mon Weather Rev 117:231-235. doi:10.1175/ 1520-0493(1989)117<0231:AIWSA > 2.0.CO;2

Vizy EK, Cook KH (2002) Development and application of a mesoscale climate model for the tropics: influence of sea surface temperature anomalies on the West African monsoon. J Geophys Res 107. doi:10.1029/2001JD000686

Vizy EK, Cook KH (2003) Connections between the summer east African and Indian rainfall regimes. J Geophys Res 108. doi: 10.1029/2003JD003452

Vizy EK, Cook KH (2005) Evaluation of Last Glacial Maximum sea surface temperature reconstructions through their influence on
South American climate. J Geophys Res 110. doi:10.1029/ 2004JD005415

Ward MN (1998) Diagnosis and short-lead time prediction of summer rainfall in Tropical North Africa at interannual and multidecadal timescales. J Clim 11:3167-3191. doi:10.1175/1520-0442(1998) 011<3167:DASLTP $>2.0 . C O ; 2$

Xue YK, Shukla J (1993) The influence of land-surface properties on Sahel climate. 1. Desertification. J Clim 6(12):2232-2245. doi: 10.1175/1520-0442(1993)006<2232:TIOLSP > 2.0.CO;2

Xue YK, Shukla J (1996) The influence of land surface properties on Sahel climate. 2. Afforestation. J Clim 9(12):3260-3275. doi: 10.1175/1520-0442(1996)009<3260:TIOLSP > 2.0.CO;2

Zeng N, Neelin JD, Lau KM, Tucker CJ (1999) Enhancement of interdecadal climate variability in the Sahel by vegetation interaction. Science 286:1537-1540. doi:10.1126/science.286. 5444.1537 